\title{
ESTADO DA ARTE DAS PRODUÇÕES STRICTO SENSU EM EDUCAÇÃO DE JOVENS E ADULTOS NA BAHIA ENTRE 2007 - 2017
}

\author{
STATE OF THE ART OF PRODUCTION STRICTO SENSU IN YOUTH \\ AND ADULT EDUCATION IN BAHIA BETWEEN 2007 - 2017
}

\author{
ESTADO DEL ARTE DE PRODUCCIÓN STRICTO SENSU EN \\ EDUCACIÓN JUVENIL Y ADULTA EN BAHIA ENTRE 2007 - 2017
}

\author{
Profa. Ma. Selma dos Santos ${ }^{1}$ \\ Profa. Ma. Katiuscia da Silva Santos ${ }^{2}$ \\ Prof. Dr. Eduardo José Fernandes Nunes ${ }^{3}$ \\ Larissa Sousa Silva de Jesus ${ }^{4}$
}

\begin{abstract}
RESUMO
O presente artigo versa sobre a produção científica em nível de Pós-graduação stricto sensu sobre a Educação de Jovens e Adultos realizada na Bahia entre os anos de 2007 a 2017. Neste artigo, apresentamos os resultados parciais do projeto de pesquisa Gestão Social de Políticas Públicas de Educação de Jovens e Adultos na Bahia - 2007 a 2017, coordenado pelo grupo de pesquisa Teoria Social e Projeto Político Pedagógico através do subprojeto: Análise sociológica da formação na EJA na Bahia 2007-2017, estruturado como projeto de Iniciação Científica através da Universidade do Estado da Bahia - UNEB, Departamento de Educação, campus I - DEDC I e do Programa de Pós-graduação em Educação e Contemporaneidade PPGEDUC. O projeto possui como objetivo central a análise sociológica dos caminhos percorridos pela Educação de Jovens e Adultos (EJA) na Bahia dentro de um recorte temporal determinado, analisando três universidades baianas - Universidade do Estado da Bahia - UNEB, Universidade Federal da Bahia - UFBA, e Universidade Estadual de Feira de Santana - UEFS nos programas de Pós-graduação em Educação. O estudo mesmo não apresentando os resultados finais do Projeto, possibilita reflexões sobre a formação na EJA na Bahia.
\end{abstract}

\footnotetext{
${ }^{1}$ Professora assistente da Universidade Estadual de Feira de Santana - UEFS. Doutoranda do Programa de Pósgraduação em Educação e Contemporaneidade. Membro do Grupo de Pesquisa Teoria Social e Projeto Pedagógico - TSPPP. Membro do Núcleo de Pesquisa Formação de Professores - NUFOP/UEFS. E-mail: selmapibiduefs@gmail.com

${ }^{2}$ Doutoranda do Programa Multi-Institucional e Multidisciplinar em Difusão do Conhecimento - UFBA. Membro do Grupo de Pesquisa Teoria Social e Projeto Pedagógico - TSPPP. Professora da Educação Básica. Email: katymssantos@gmail.com

${ }^{3}$ Professor adjunto da Universidade do Estado da Bahia - UNEB. Programa de Pós-graduação em Educação e Contemporaneidade. Vice-coordenador do Grupo de Pesquisa Teoria Social e Projeto Pedagógico. E-mail: eduardojosf2@gmail.com

${ }^{4}$ Estudante da Graduação em Ciências Sociais. Iniciação Científica da Universidade do Estado da Bahia UNEB. Membro do Grupo de Pesquisa Teoria Social e Projeto Pedagógico - TSPPP. E-mail: larissa.ciso.2019@gmail.com
} 
Palavras-chave: Educação de Jovens e Adultos. Estado da Arte. Universidades Públicas da Bahia.

\begin{abstract}
This article deals with scientific production at the strict sensu Postgraduate level on Youth and Adult Education carried out in Bahia between 2007 and 2017. The production is a product of the partial results of Scientific Initiation research project of the State University of Bahia entitled Social Management of Public Policies of Youth and Adult Education in Bahia - 2007 to 2017 and the subproject: Sociological Analysis of Education in EJA in Bahia. This project has as its central objective the sociological analysis of the paths that Youth and Adult Education (EJA) in Bahia has taken within a given time frame (2007 - 2017). The research used in this study shows only three universities in Bahia - Bahia State University - UNEB, Federal University of Bahia - UFBA, Feira de Santana State University - UEFS, and Santa da Cruz State University (UESC) - with in order to answer one of the subproject's questions: What were themes published? Surveying the academic productions in the postgraduate programs in Education and its main themes studied.
\end{abstract}

Keywords: Youth and Adult Education. State of art. Strict sensu production. Scientific production. Public Universities of Bahia.

\title{
RESUMEN
}

Este artículo trata sobre la producción científica en el nivel estricto de posgrado en Educación Juvenil y de Adultos realizada en Bahia entre 2007 y 2017. La producción es producto de los resultados parciales del proyecto de investigación de Iniciación Científica del Universidad Estatal de Bahía titulada Gestión social de las políticas públicas de educación de jóvenes y adultos en Bahía - 2007 a 2017 y el subproyecto: Análisis sociológico de la educación en EJA en Bahía. Este proyecto tiene como objetivo central el análisis sociológico de los caminos que la Educación de Jóvenes y Adultos (EJA) en Bahía ha tomado en un plazo determinado (2007 - 2017). La investigación utilizada en este estudio muestra solo cuatro universidades bahianas - Universidad Estatal de Bahía - UNEB, Universidad Federal de Bahía - UFBA, Universidad Estatal Feira de Santana - UEFS y Universidad Estatal de Santa Cruz (UESC) - con para responder una de las preguntas del subproyecto: ¿Qué temas se publicaron? Encuestando las producciones académicas en los programas de posgrado en Educación y sus principales temas estudiados.

Palabras clave: Educación de jóvenes y adultos. Estado del arte. Estricta producción sensual. Producción científica Universidades Públicas de Bahía.

\section{INTRODUÇÃO}

O presente artigo apresenta resultados parciais da pesquisa Gestão Social de Políticas Públicas de Educação de Jovens e Adultos na Bahia - 2007 a 2017 que objetiva analisar as políticas públicas destinadas à Educação de Jovens e Adultos na Bahia, explicitando os 
pressupostos sociológicos, financeiros, políticos-pedagógicos e a concepção de Homem e Estado que orientam as formulações governamentais. A mesma fortalece os resultados da pesquisa desenvolvida no âmbito do Observatório de Educação de Jovens e Adultos no Território do Sisal (OBEJA), no período de 2012 a 2015, pois aprofunda a investigação sobre o "Balanço do financiamento da Educação de Jovens e Adultos na Bahia no período de 2007 a $2017^{5 "}$ e a "Análise sociológica da formação na Educação de Jovens e Adultos da Bahia" com intuito de compreender as concepções sociológicas e educacionais que orientam as formulações governamentais e suas interfaces com as dinâmicas econômicas nos financiamentos e proposições de políticas públicas de formação para sujeitos da Educação de Jovens e Adultos - EJA. A metodologia utilizada é a revisão bibliográfica operacionalizada mediante a busca nos repositórios das universidades baianas. Apresentaremos os dados parciais obtidos sobre estudos de mestrado e doutorado em educação realizados em três universidades baianas (Universidade do Estado da Bahia - UNEB, Universidade Federal da Bahia - UFBA, e Universidade Estadual de Feira de Santana - UEFS) no período de 2007 a 2017 sobre a Educação de Jovens e Adultos. São estudos que contribuem para colocar a Educação de Jovens e Adultos no cenário das preocupações das propostas governamentais quando se pensa as políticas públicas educacionais.

\section{UM PANORAMA DA EDUCAÇÃO DE JOVENS E ADULTOS}

A Educação de Jovens e Adultos no país nunca foi prioridade, e a modalidade sempre desprestigiada. Quando se propõe pensar as pesquisas científicas, dentre das universidades, o quantitativo de produções ainda é pouco em relação às problemáticas que merecem ser desveladas. O Brasil tem se destacado negativamente na Educação quando se pensa em acesso a todos, o número de analfabetismo ainda é grande, e, ao se pensar o número de pessoas jovens e adultas com o abandono escolar precoce, é ainda maior. É verdade que os índices de analfabetismo vêm caindo ano a ano, e muito se deve às tensões impostas pelos movimentos sociais que contribuíram para ampliação do acesso de adultos à educação escolarizada.

E em pleno século XXI questões relacionadas ao acesso, que outrora se imaginava ter superado no país, voltam à tona com grande quantitativo de fechamento turmas de EJA, e em

\footnotetext{
${ }^{5}$ Resultados do estudo estão publicados em artigo SANTOS, Selma; NUNES, Eduardo José Fernandes; DANTAS, Jorge Filipe Carneiro Coelho. Avanços, recuos ou estagnação do financiamento da Educação de Jovens e Adultos na Bahia - 2007 a 2017? In: Revista Educação e Ciências Sociais. v. 1 n. 2 (2019). p. 05 25. ISSN 2595-9980. Disponível em:

https://www.revistas.uneb.br/index.php/cienciassociais/issue/view/318/showToc
}

Revista Educação e Ciências Sociais (ISSN: 2595-9980), Salvador, v.3, n.4, 2020 
especial de escolas rurais. Discussões de permanência dividem ainda espaço a necessidade recorrente de acesso desses sujeitos que tiveram seus direitos de educação escolar negados em tempo mais jovial.

Desde a Lei de Diretrizes e Bases da Educação (Lei $n^{\circ}$. 9394/96) que se iniciam os pensamentos às especificidades da EJA, mas só apenas em $2000\left(\mathrm{CNE} / \mathrm{CEB} \mathrm{n}^{\circ}\right.$. 1/2000) que se implantaram as Diretrizes e Bases Curriculares da Educação de Jovens e Adultos. Outros importantes avanços para EJA na Legislação Brasileira foi em 2004 com a instituição do Programa de Apoio ao Transporte Escolar (Lei n ${ }^{\circ}$ 10.880/2004) e repasses para o Programa Brasil Alfabetizado, como também em 2009 com a resolução CD/ FNDE nº 51/2009 que dispõe sobre o Programa Nacional do Livro Didático para a Educação de Jovens e Adultos (PNLDEJA); 2010, com a instituição das Diretrizes Operacionais para a Educação de Jovens e Adultos; 2014 com o Plano Nacional da Educação - PNE veio instituir metas específicas para a EJA (metas 8, 9, 10 e 11). E concluindo, em 2017, com a com a inclusão da EJA nos recursos da Merenda Escolar (Resolução CD/FNDE/MEC, nº 5).

Conquistas diversas tencionadas pelo movimento social e universidades que promoveram movimentos, fóruns (Fóruns da Escola Pública em 1990 e Fóruns da Educação de Jovens e Adultos a partir de 1996), encontros (ENEJA a partir de 1999), reuniões e conferências (Conferências Internacionais de Educação de Adultos - CONFINTEA, a partir de 1997), bem como a Cátedra da UNESCO em Educação de Jovens e Adultos, contando com auxílio de Organismo Internacionais, a exemplo da Organização das Nações Unidas - ONU através da Organização das Nações Unidas para Educação, Ciência e Cultura - UNESCO; Banco Mundial (Comissão Econômica para América Latina); Barco Internacional de Reconstrução e de Desenvolvimento (BIRD); Organização Internacional do Trabalho, dentre outras.

Contudo, o Governo Federal vem a cada dia desassistindo a essa população com o fechamento e extinção de setores que promoviam a igualdade e acesso dessa população mais carente a direitos, como a escolarização, a exemplo do menor investimento no valor aluno da EJA e extinção SECADI, o não subsídio ao PNLDEJA (Plano Nacional do Livro Didático da Educação de Jovens e Adultos), o que vem a cada ano desprovendo os municípios e sucateando a modalidade. Neste contexto, é importante se pensar sobre o papel que a universidade vem desempenhando no enfrentamento e na reflexão de tantas outras problemáticas que envolvem a EJA.

É perceptível que é crescente o número de pesquisas na área, tendo em vista a desvinculação da Educação de Jovens e Adultos do eixo da Educação Popular. Como também 
implantação de diversos Observatórios de Educação em parceria com o Capes, INEP, OBEDUC e fundações estaduais de amparo a pesquisa (FAPERJ, FAPESB) a exemplo do dos Observatórios Diagnóstico da qualidade de ensino na Educação de Jovens e Adultos: um estudo de caso no Rio de Janeiro ${ }^{6}$ e Observatório da Educação de Jovens e Adultos do Território de Identidade do Sisal - OBEJA ${ }^{7}$. Além de diversos Núcleos de pesquisa em $\mathrm{EJA}^{8}$.

Para o ensino, pesquisa e extensão em EJA, há diversas ações que as universidades vêm propondo no Brasil, tanto em nível de graduação quanto em Pós-graduação. Dentre elas destacamos as ações Lato Sensu (veja tabela 1) e na modalidade Stricto Sensu o Mestrado Profissional em Educação de Jovens e Adultos (MPEJA) da Universidade do Estado da Bahia (UNEB), autorizado através da Resolução no 902/12, funcionamento no DEDC/Campus I Salvador e a Resolução n⿳ 1327/18 que autoriza a criação do Doutorado Profissional em Educação de Jovens e Adultos (EJA), vinculado ao Programa de Pós-Graduação stricto sensu Educação de Jovens e Adultos (EJA), DEDC/Campus I - Salvador.

Tabela 1: Curso Lato Sensu em EJA.

\begin{tabular}{|c|c|}
\hline Universidade/Ano & Curso Lato Sensu \\
\hline UNIPANPA/2011 & EJA em Território de Fronteira \\
\hline UFBA / 2011 & Especialização em EJA \\
\hline UNEB/2011 Campus X & Especialização em Educação de Jovens e Adultos \\
\hline UNB/2014 & $\begin{array}{l}\text { Especialização em Educação na Diversidade e Cidadania } \\
\text { com ênfase em EJA }\end{array}$ \\
\hline IFRN/ 2015 & $\begin{array}{l}\text { Especialização em Educação de Jovens e Adultos no } \\
\text { contexto da Diversidade }\end{array}$ \\
\hline UFPB/2015 & $\begin{array}{l}\text { Educação de Jovens e Adultos na Diversidade e Inclusão } \\
\text { Social }\end{array}$ \\
\hline
\end{tabular}

Muitas são as produções oriundas dos programas e ações das universidades, contudo neste trabalho nos atentaremos as universidades da Bahia, visto que se trata de uma produção que surge como produto parcial do Projeto de Iniciação Científica intitulado: Gestão Social de Políticas Públicas de Educação de Jovens e Adultos na Bahia - 2007 a 2017. E, por se

\footnotetext{
${ }^{6}$ Projeto interinstitucional - Unicamp, UERJ e UFJF (2011 a 2013)

${ }^{7}$ www.obeja.uneb.br

$8 \longdiv { 3 9 \text { Núcleos segundo o Fórum EJA Brasil. (www.forumeja.org.br) } }$
} 
tratar de uma pesquisa ainda em curso, escolhemos o recorte das produções em nível de Mestrado (dissertações) e de doutorado (teses) nas universidades baianas Universidade do Estado da Bahia - UNEB, Universidade Federal da Bahia - UFBA e Universidade Estadual de Feira de Santana - UEFS, pesquisa realizada nos repositórios de cada universidade.

\section{ANÁLISE SOCIOLÓGICA DA FORMAÇÃO NA EJA NA BAHIA}

A pesquisa Gestão Social de Políticas Públicas de Educação de Jovens e Adultos na Bahia - 2007 a 2017, é uma pesquisa realizada pelo Observatório de Educação de Jovens e Adultos (OBEJA), vinculado ao Programa de Pós-Graduação em Educação e Contemporaneidade da Universidade do Estado da Bahia, através de dois subprojetos, o "Balanço do financiamento da Educação de Jovens e Adultos na Bahia no período de 2007 a 2017"9 e a "Análise sociológica da formação na Educação de Jovens e Adultos na Bahia 2007 a 2017" com intuito de compreender as ações governamentais sobre a Educação de Jovens e Adultos - EJA no território baiano.

O subprojeto Análise sociológica da formação na EJA na Bahia faz parte do projeto de pesquisa Gestão Social de Políticas Públicas de Educação de Jovens e Adultos na Bahia 2007 a 2017, e tem como objetivo alcançar metas e responder questões determinadas por meio do processo do tipo de pesquisa atrelada ao conceito de estado da arte, visando de forma sociológica os caminhos que a EJA tem enfrentado, dentro de um recorte temporal determinado (2007 - 2017). Como passo inicial, temos o levantamento das produções acadêmicas das universidades baianas - UNEB, UFBA, UEFS - em seguida, a análise cuidadosa das produções, objetivando responder: 1. Quais temas foram publicados? 2. Identificar as políticas públicas e seus pressupostos, e 3. Quais políticas públicas foram mais pesquisadas dentro desse recorte. Fundamentado em textos complementares e importantes para o desenvolvimento do trabalho, são eles: o artigo "O estado da arte da pesquisa sobre o fracasso escolar (1991 - 2002): Um estudo introdutório”, conceituando o estado da arte, possibilitando uma atenção detalhada e bem orientada, o texto de Gilmar Evandro Szcezepanik "A ciência e seus métodos: entre o monismo e o pluralismo metodológico"; o ensaio de Maria Clara Di Pierro e Sérgio Haddad “Transformações nas políticas de Educação de Jovens e Adultos no Brasil no início do $3^{\circ}$ milênio: Uma análise das agendas nacional e

\footnotetext{
${ }^{9}$ Disponível em: https://www.revistas.uneb.br/index.php/cienciassociais/article/view/7510/4954
} 
internacional" e a pesquisa de Maria Hermínia Lage Fernandes Laffin e Tânia Regina Dantas A pesquisa sobre a EJA na e da Bahia: aproximações e demandas teórico-metodológicas.

Considerando o estado da arte como diretriz para o desenvolvimento do projeto e destacando metodologicamente o processo do campo de pesquisa para este tipo, foi proposta a realização da pesquisa em três etapas (ver figura 1): em primeiro lugar, o levantamento dos dados em repositórios, sites e bibliotecas universitárias; em segundo, a seleção dos trabalhos segundo a necessidade do projeto de pesquisa, realizando a leitura e análise dos resumos, verificando dessa forma as informações das mesmas: temas, palavras-chave, objetivos, problemáticas, metodologias e os resultados, organizando e sistematizando as informações por instituições, recorte temporal, temas, metodologias e resultados. E, por fim, realizar a análise e interpretação dos dados sistematizados para elaboração do relatório final.

Figura 1: Processo inicial da pesquisa: 3 fases do desenvolvimento metodológico.

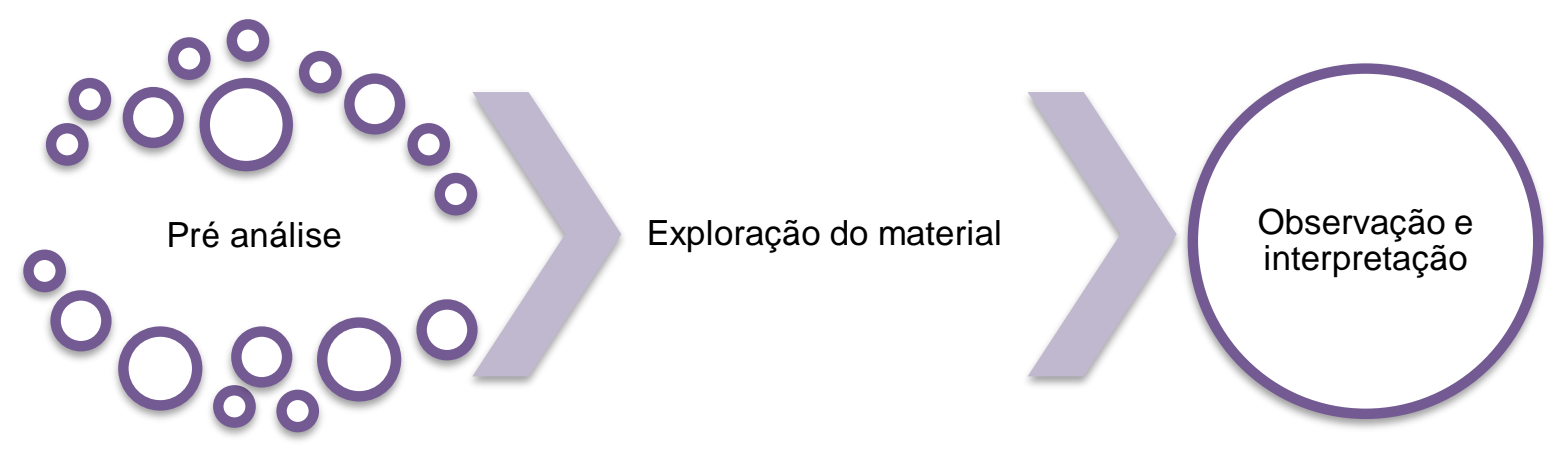

Fonte: Autores, 2020.

Inicialmente, foram pesquisados bancos de dados, chamados repositórios, e só então, houve o levantamento das produções acadêmicas (artigos publicados em periódicos, teses de doutorado, dissertações de mestrado, livros, trabalhos apresentados em eventos) por meio das palavras-chave: EJA; Educação de Jovens e Adultos; Jovens e Adultos. Foram identificadas após o levantamento e contagem dessas produções, foi realizada a pré-análise, em seguida, a exploração do material encontrado e em último, a observação do que foi obtido, e ainda, podem-se organizar os dados em tabelas e gráficos para melhor visualização e interpretação dos mesmos. 
ESTADO DA ARTE DAS PRODUÇÕES STRICTO SENSU EM EDUCAÇÃO DE JOVENS E ADULTOS NA BAHIA

Esse momento está caracterizado pela análise mais aprofundada dos dados coletados sobre o estado da arte da Educação de Jovens e Adultos de estudos acadêmicos em dissertações e teses realizados nas universidades baianas. Essa etapa funciona como demonstrativo das produções acadêmicas.

A partir dos procedimentos de levantamento de literatura, das produções acadêmicas organiza-se o estado da arte. A Revisão de Literatura foi realizada no período de agosto de 2018 a junho de 2019, o que possibilita a compreensão do estado atual do conhecimento acerca do tema educação de jovens e adultos, formação na educação de jovens e adultos.

\begin{abstract}
A importância de balanços periódicos do estado de coisas vigente numa área de pesquisa é múltipla. Eles podem detectar teoria e método dominantes; pôr em relevo aspectos do objeto de estudo que se esboçam nas entrelinhas das novas pesquisas; revelar em que medida a pesquisa recente relaciona-se com a anterior e vai tecendo uma trama que permita avançar na compreensão do objeto de estudo pela via do real acréscimo ao que já se conhece ou da superação de concepções anteriores. (ANGELUCCI; KALMUS; PAPARELLI; PATTO, 2004, p. 53).
\end{abstract}

A análise considerou os periódicos e artigos que tratam sobre a Educação de Jovens e Adultos. Vejamos os quadros 1 e 2 :

Quadro 01: Periódicos que tratam sobre a Educação de Jovens e Adultos.

\begin{tabular}{|c|c|}
\hline PERIÓDICO & ENDEREÇO ELETRÔNICO \\
\hline $\begin{array}{c}\text { Revista Brasileira de } \\
\text { Educação de Jovens e } \\
\text { Adultos. }\end{array}$ & https://www.revistas.uneb.br/index.php/educajovenseadultos \\
\hline $\begin{array}{c}\text { EJA em Debate - Portal de } \\
\text { Periódicos do IFSC. }\end{array}$ & https://periodicos.ifsc.edu.br/index.php/EJA \\
\hline $\begin{array}{c}\text { Educação de Jovens e } \\
\text { Adultos - SciELO. }\end{array}$ & http://www.scielo.br/pdf/ccedes/v35n96/1678-7110-ccedes-35-96- \\
& $00173 . p d f$ \\
\end{tabular}

Quadro 02: Artigos lidos sobre a Educação de Jovens e Adultos.

\begin{tabular}{|l|l|}
\hline \multicolumn{1}{|c|}{ ARTIGO } & \multicolumn{1}{|c|}{ ENDEREÇO ELETRÔNICO } \\
\hline $\begin{array}{l}\text { Educação de Jovens e Adultos: uma história de } \\
\text { complexidade e tensões - Marisa Narcizo } \\
\text { Sampaio. }\end{array}$ & $\begin{array}{l}\text { http://periodicos.uesb.br/index.php/praxis/artic } \\
\text { le/view/241/253 }\end{array}$ \\
\hline $\begin{array}{l}\text { A Educação de Jovens e Adultos como } \\
\text { Instrumento de Transformação Social - Gilson } \\
\begin{array}{l}\text { Luiz Rodrigues Souza, Luziene Aparecida da } \\
\text { Silva. }\end{array}\end{array}$ & $\begin{array}{l}\text { http://periodicos.cesg.edu.br/index.php/educac } \\
\text { aoecultura/article/view/74 }\end{array}$ \\
\hline $\begin{array}{l}\text { Práticas de Letramento na Educação de } \\
\text { Jovens e Adultos - Nilcéa Lemos Pelandré, } \\
\text { Paula Alves de Aguiar. }\end{array}$ & https://periodicos.ufsc.br/index.php/forum/artic \\
\end{tabular}


Estado da arte das produções stricto sensu em educação de jovens e adultos na ...

\begin{tabular}{|c|c|}
\hline ARTIGO & ENDEREÇO ELETRÔNICO \\
\hline $\begin{array}{l}\text { A produção sobre a educação da mulher na } \\
\text { educação de jovens e adultos - Maria Clarisse } \\
\text { Vieira, Karla Nascimento Cruz. }\end{array}$ & $\begin{array}{l}\text { https://periodicos.ufsm.br/reveducacao/article/ } \\
\text { view/20116 }\end{array}$ \\
\hline $\begin{array}{l}\text { Educação de Jovens e Adultos e Inclusão } \\
\text { Social: uma análise dos artigos sobre Educação } \\
\text { de Jovens e Adultos publicados no periódico } \\
\text { "Educar em Revista" - Denise Teberga } \\
\text { Mendanã, Maria Aparecida Campos Diniz de } \\
\text { Castro. }\end{array}$ & $\begin{array}{l}\text { http://www.unitau.br/files/arquivos/category_1 } \\
\text { 54/MCH1100_1427389126.pdf }\end{array}$ \\
\hline $\begin{array}{l}\text { A pesquisa sobre a EJA na e da Bahia: } \\
\text { aproximações e demandas teórico- } \\
\text { metodológicas. Revista Brasileira de Educação } \\
\text { de Jovens e Adultos, Bahia - Maria Hermínia } \\
\text { Lage Fernandes Laffin; Tânia Regina Dantas. }\end{array}$ & $\begin{array}{l}\text { https://www.revistas.uneb.br/index.php/educaj } \\
\text { ovenseadultos/article/view/2139 }\end{array}$ \\
\hline
\end{tabular}

No estudo também foi considerado o portal de catálogo de teses e dissertações da CAPES (http://catalogodeteses.capes.gov.br/catalogo-teses/). Para o levantamento de dados foi criado o Quadro - Publicações de Teses e Dissertações Portal Capes - 2007 - 2017 que consta: ano/instituição, programa; autoria/tipo de produção; título; palavras-chave; fundamentação teórica; contexto. As teses e as dissertações que constam no catálogo após março de 2014 trazem "detalhes" e neles quase em 100\% o resumo responde aos dados solicitados.

A língua portuguesa foi escolhida como filtro para o levantamento de dados. E a palavra-chave geral foi Educação de Jovens e Adultos e EJA, com consulta a seiscentos depósitos. As palavras-chave de busca utilizadas foram:

Busca 01: Educação de Jovens e Adultos (18600 estudos)

Busca 02: EJA (1612 estudos)

Gráfico 1: Número de estudos por buscador no catálogo CAPES (2007-2017).

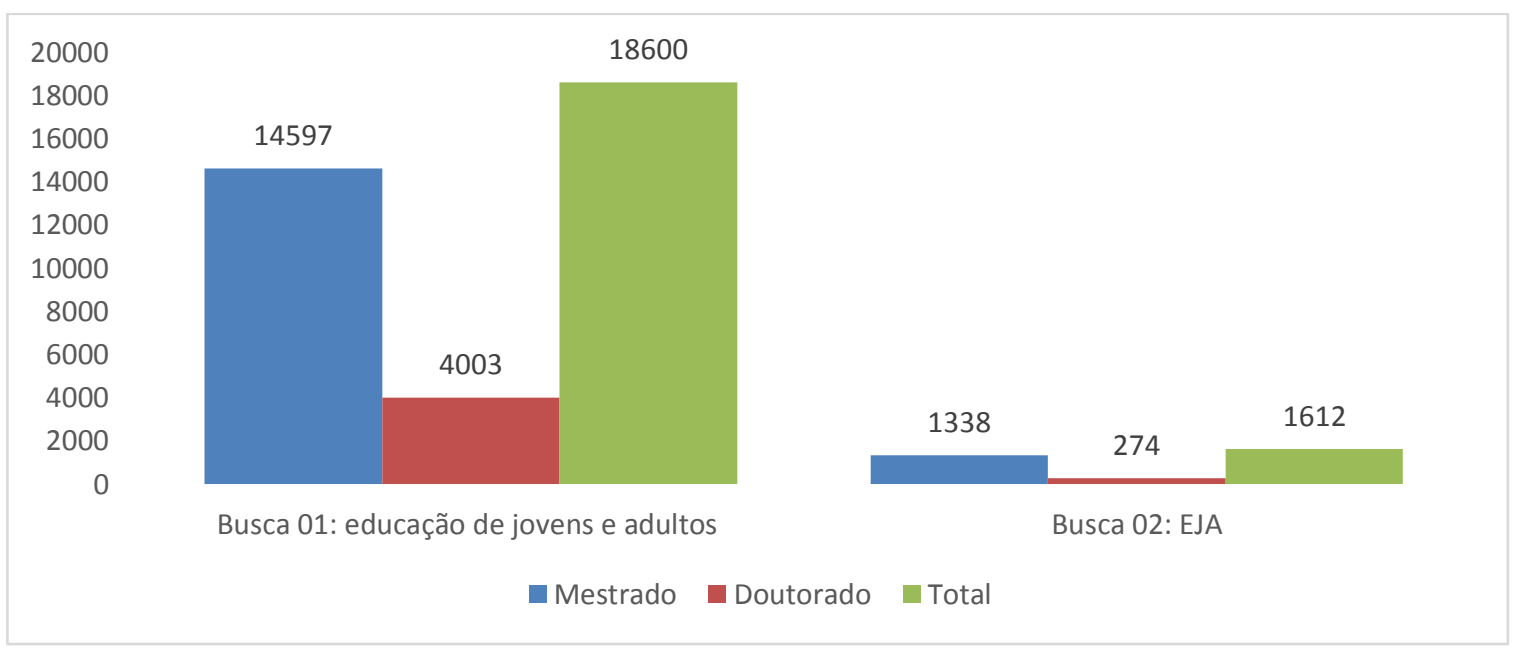

Fonte: CAPES, 2019.

Revista Educação e Ciências Sociais (ISSN: 2595-9980), Salvador, v.3, n.4, 2020 
Ao refinar os resultados das produções no catálogo da CAPES, consultando apenas as Universidades baianas citadas, foi possível identificar 37 trabalhos, devido ao grande número de produções catalogadas. Portanto, para a realização de um levantamento mais detalhado do estado da arte das produções, foi necessário realizar visitas aos sites dos repositórios institucionais específicos das universidades: Universidade do Estado da Bahia - UNEB, Universidade Federal da Bahia - UFBA e Universidade Estadual de Feira de Santana - UEFS, analisando as produções de Teses e Dissertações dos programas de Educação. Foram eles:

Quadro 03: Repositórios de Pós-Graduação em Educação Consultados.

\begin{tabular}{|c|c|}
\hline Instituição & Programas \\
\hline \multirow{3}{*}{$\begin{array}{l}\text { UNEB } \\
\text { Universidade do Estado da Bahia }\end{array}$} & $\begin{array}{l}\text { Mestrado Profissional em Educação de Jovens e Adultos - } \\
\text { MPEJA }\end{array}$ \\
\hline & $\begin{array}{c}\text { Programa de Pós Graduação em Educação e } \\
\text { Contemporaneidade - PPGEDUC }\end{array}$ \\
\hline & $\begin{array}{c}\text { Mestrado Profissional em Gestão e Tecnologia Aplicadas à } \\
\text { Educação - GESTEC }\end{array}$ \\
\hline \multirow{3}{*}{$\begin{array}{c}\text { UFBA } \\
\text { Universidade Federal da Bahia }\end{array}$} & $\begin{array}{c}\text { Mestrado Profissional em Educação: Currículo, Linguagens } \\
\text { e Inovações Pedagógicas - MPED }\end{array}$ \\
\hline & Programa de Pós Graduação em Educação - PPGE \\
\hline & $\begin{array}{l}\text { Programa de Pós Graduação Multidisciplinar e Multi- } \\
\text { Institucional em Difusão do Conhecimento - DMMDC }\end{array}$ \\
\hline $\begin{array}{c}\text { UEFS } \\
\text { Universidade Estadual de Feira de } \\
\text { Santana } \\
\end{array}$ & Mestrado em Educação \\
\hline
\end{tabular}

Fonte: Elaboração própria baseada nos dados.

Quadro 04: Produções acadêmicas por universidades baianas relacionadas à Educação de Jovens e Adultos.

\begin{tabular}{|c|c|}
\hline Universidades baianas & $\begin{array}{c}\text { Número de produções acadêmicas encontradas } \\
\text { nos repositórios }\end{array}$ \\
\hline $\begin{array}{c}\text { Universidade Estadual de Feira de Santana - } \\
\text { UEFS }\end{array}$ & 6 \\
\hline Universidade Federal da Bahia - UFBA & 33 \\
\hline Universidade do Estado da Bahia - UNEB & 96 \\
\hline
\end{tabular}

Fonte: Elaboração própria baseada nos dados.

\section{UNIVERSIDADE DO ESTADO DA BAHIA - UNEB}

As pesquisas em Educação de Jovens e Adultos realizadas na Universidade do Estado da Bahia são encontradas em diversos programas, para compor o quadro de estudos desta 
universidade foi considerado o quadro dos estudos de Laffin e Dantas $(2015)^{10}$, e realizada consulta ao site do Centro de Documentação e Informação (CDI). No referido portal é possível encontrar as produções de três programas em Educação: o Mestrado Profissional em Educação de Jovens e Adultos - MPEJA, Mestrado Profissional em Gestão e Tecnologia Aplicadas à Educação - GESTEC e o PPGEDUC (Programa de Pós-Graduação em Educação e Contemporaneidade), além dos Programas citados, é possível encontrar as dissertações do Programa de Pós-Graduação em Políticas Públicas, Gestão do Conhecimento e Desenvolvimento Regional - PPGDR (trabalho do PPGDR, não foram analisados aqui). Para realizar a busca foi necessário selecionar o programa e só após indicar no buscador a palavrachave desejada. Vejamos os quadros com as produções:

Quadro 05: Produções Stricto Sensu por temporalidade a UNEB

\begin{tabular}{|l|c|c|c|c|}
\hline \multicolumn{1}{|c|}{ Ano } & MPEJA & $\begin{array}{c}\text { PPGEDUC } \\
\text { DISSERTAÇÃO }\end{array}$ & $\begin{array}{c}\text { PPGEDUC } \\
\text { TESE }\end{array}$ & GESTEC \\
\hline 2007 & - & 41 & - & - \\
\hline $\mathbf{2 0 0 8}$ & - & 34 & 3 & - \\
\hline $\mathbf{2 0 0 9}$ & - & 40 & 1 & - \\
\hline $\mathbf{2 0 1 0}$ & - & 38 & 0 & - \\
\hline $\mathbf{2 0 1 1}$ & - & 36 & 0 & - \\
\hline $\mathbf{2 0 1 2}$ & - & 31 & 1 & - \\
\hline $\mathbf{2 0 1 3}$ & - & 39 & 13 & - \\
\hline $\mathbf{2 0 1 4}$ & - & 24 & 15 & - \\
\hline $\mathbf{2 0 1 5}$ & 23 & 33 & 18 & - \\
\hline $\mathbf{2 0 1 6}$ & 27 & 33 & 13 & 58 \\
\hline $\mathbf{2 0 1 7}$ & 13 & 30 & 19 & 45 \\
\hline Total & 63 & 379 & 83 & 103 \\
\hline
\end{tabular}

Fonte: Elaboração própria baseada nos dados do CDI (2019).

Nos programas analisados há 628 produções Stricto Sensu publicadas no repositório do CDI, das quais se pode observar a temática de Educação de Jovens e Adultos em 96. Detalhadas no gráfico a seguir:

\footnotetext{
${ }^{10}$ As autoras apresentam dados dos programas: Programa de Pós Graduação em Educação e Contemporaneidade, Mestrado Profissional em Gestão e Tecnologia Aplicadas à Educação, Mestrado Profissional em Educação de Jovens e Adultos, Mestrado Acadêmico em Estudo de Linguagens, Mestrado Profissional em Letras, Mestrado em Crítica Cultural, e do Mestrado Profissional em Educação e Diversidade.
} 
Gráfico 2: Número de estudos em EJA por Programa analisado - UNEB (2007-2017).

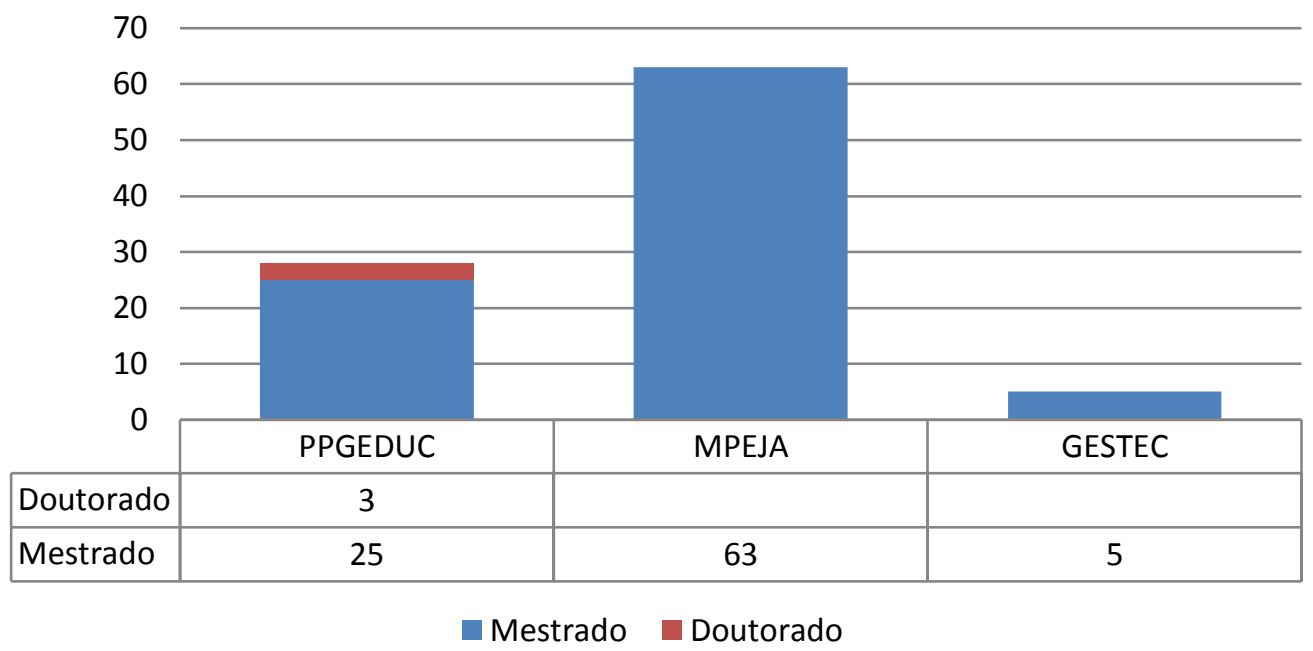

Fonte: Elaboração própria baseada nos dados.

Conforme observado no gráfico 2, entre os anos de 2007 e 2017 foram publicadas 93 dissertações e apenas 3 teses com a temática de Educação e Jovens e Adultos. No quadro a seguir apontamos os títulos das 33 produções catalogadas no CDI (Mestrado e Doutorado em Educação e Contemporaneidade e Mestrado Profissional em Gestão e Tecnologia Aplicadas à Educação), acrescida de 09 produções, catalogadas a partir do texto de Laffin e Dantas (2015, p. 154-157) (Mestrado Acadêmico em Estudo de Linguagens, Mestrado Profissional em Letras, Mestrado em Crítica Cultural, e do Mestrado Profissional em Educação e Diversidade), com exceção das produções do MPEJA, que estão detalhadas no quadro 06, observe:

Quadro 06: Dissertações e Teses Catalogadas no período de 2007 e 2017.

\begin{tabular}{|c|l|c|c|}
\hline$N^{\circ}$ & Título & Ano & Programa \\
\hline $\mathbf{0 1}$ & $\begin{array}{l}\text { Um estudo de caso sobre duas expressões } \\
\text { contraditórias na comunidade de atendimento } \\
\text { socioeducativo (CASE) - Escola regular e oficinas } \\
\text { profissionalizantes. }\end{array}$ & $\begin{array}{l}\text { Mestrado em Educação } \\
\text { e Contemporaneidade. }\end{array}$ \\
\hline $\mathbf{0 2}$ & $\begin{array}{l}\text { Dá licença d'eu falá?: os entrelugares da competência } \\
\text { comunicativa de jovens e adultos. }\end{array}$ & 2007 & $\begin{array}{l}\text { Mestrado em Educação } \\
\text { e Contemporaneidade. }\end{array}$ \\
\hline $\mathbf{0 3}$ & $\begin{array}{l}\text { Escola para que te quero? Marcas da escola em } \\
\text { adolescentes privados de liberdade por prática de ato } \\
\text { infracional. }\end{array}$ & $\begin{array}{l}\text { Mestrado em Educação } \\
\text { e Contemporaneidade. }\end{array}$ \\
\hline $\mathbf{0 4}$ & $\begin{array}{l}\text { Isso eu não aprendi na escola: uma escuta das } \\
\text { representações sociais do educador numa práxis de } \\
\text { protagonismo juvenil. }\end{array}$ & $\begin{array}{l}\text { Mestrado em Educação } \\
\text { e Contemporaneidade. }\end{array}$ \\
\hline $\mathbf{0 5}$ & $\begin{array}{l}\text { Trabalhadoras domésticas em um condomínio de } \\
\text { Salvador: saberes e fazeres matemáticos em suas } \\
\text { histórias de vida. }\end{array}$ & 2007 & $\begin{array}{l}\text { Mestrado em Educação } \\
\text { e Contemporaneidade. }\end{array}$ \\
\hline
\end{tabular}


Estado da arte das produções stricto sensu em educação de jovens e adultos na ...

\begin{tabular}{|c|c|c|c|}
\hline $\mathrm{N}^{\circ}$ & Título & Ano & Programa \\
\hline 06 & $\begin{array}{l}\text { A Educação de Jovens e Adultos e a Formação para a } \\
\text { Cidadania: a experiência do Programa Alfabetização } \\
\text { Solidária. }\end{array}$ & 2007 & $\begin{array}{l}\text { Mestrado em Educação } \\
\text { e Contemporaneidade }\end{array}$ \\
\hline 07 & Histórias cruzadas: leituras de mulheres negras da EJA. & 2008 & $\begin{array}{l}\text { Mestrado em Educação } \\
\text { e Contemporaneidade. }\end{array}$ \\
\hline 08 & $\begin{array}{l}\text { Do cansaço da lavoura ao alívio na escola: um estudo } \\
\text { sobre quotidiano e espaços de sociabilidade de } \\
\text { estudantes da EJA do noturno, ensino médio, no } \\
\text { município de Irará - Bahia. }\end{array}$ & 2009 & $\begin{array}{l}\text { Mestrado em Educação } \\
\text { e Contemporaneidade. }\end{array}$ \\
\hline 09 & $\begin{array}{l}\text { Educar na diferença: imagens e concepções docentes } \\
\text { sobre o processo de letramento do surdo na Educação } \\
\text { de Jovens e Adultos. }\end{array}$ & 2009 & $\begin{array}{l}\text { Mestrado em Educação } \\
\text { e Contemporaneidade. }\end{array}$ \\
\hline 10 & $\begin{array}{l}\text { O teatro na Educação de Jovens e Adultos: } \\
\text { contribuições para o processo de letramento e a } \\
\text { formação da cidadania }\end{array}$ & 2009 & $\begin{array}{l}\text { Mestrado em Educação } \\
\text { e Contemporaneidade. }\end{array}$ \\
\hline 11 & $\begin{array}{l}\text { Programa TOPA/UNEB: Formação de alfabetizadores } \\
\text { e perspectiva para a inclusão sociodigital dos jovens e } \\
\text { adultos da Bahia. }\end{array}$ & $2009^{11}$ & $\begin{array}{l}\text { Mestrado em Educação } \\
\text { e Contemporaneidade. }\end{array}$ \\
\hline 12 & $\begin{array}{l}\text { Escolarização de Jovens e Adultos: análise sobre o } \\
\text { desenvolvimento dos cursos em Escolas Exclusivas da } \\
\text { rede Estadual na Cidade de Salvador - BA. }\end{array}$ & 2010 & $\begin{array}{l}\text { Mestrado em Educação } \\
\text { e Contemporaneidade. }\end{array}$ \\
\hline 13 & $\begin{array}{l}\text { Usos funcionais da escrita na história de vida dos atores } \\
\text { de EJA em uma Escola de Ilha de Maré. }\end{array}$ & 2010 & $\begin{array}{l}\text { Mestrado em Educação } \\
\text { e Contemporaneidade. }\end{array}$ \\
\hline 14 & $\begin{array}{l}\text { Percursos de vida, trajetórias escolares: narrativas } \\
\text { (auto) biográficas das mulheres do Programa de } \\
\text { Alfabetização de Jovens e Adultos de Praia Grande, } \\
\text { Ilha de Maré, Salvador - BA. }\end{array}$ & 2010 & $\begin{array}{l}\text { Mestrado em Educação } \\
\text { e Contemporaneidade. }\end{array}$ \\
\hline 15 & $\begin{array}{l}\text { A Educação de Adultos à Distância no Estado da Bahia } \\
\text { - 1961-1979: MEB, SERTE e a criação do IRDEB. }\end{array}$ & 2010 & $\begin{array}{l}\text { Mestrado em Educação } \\
\text { e Contemporaneidade. }\end{array}$ \\
\hline 16 & $\begin{array}{l}\text { Televisão e mediação: um estudo de caso com jovens } \\
\text { e adultos da Boa Vista do Lobato. }\end{array}$ & 2011 & $\begin{array}{l}\text { Mestrado em Educação } \\
\text { e Contemporaneidade. }\end{array}$ \\
\hline 17 & $\begin{array}{l}\text { Professoras negras na Educação de Jovens e Adultos: } \\
\text { identidades, memórias e docência. }\end{array}$ & 2011 & $\begin{array}{l}\text { Mestrado em Educação } \\
\text { e Contemporaneidade. }\end{array}$ \\
\hline 18 & $\begin{array}{l}\text { A Outra Margem: A Relação dos Programas de } \\
\text { Alfabetização com o Processo de Letramento dos } \\
\text { Pescadores e Pescadoras de Xique-xique. }\end{array}$ & $2012^{12}$ & $\begin{array}{l}\text { Mestrado em Educação } \\
\text { e Contemporaneidade. }\end{array}$ \\
\hline 19 & $\begin{array}{l}\text { Para cada pé, um sapato?! A educação como uma das } \\
\text { formas para reinserir o preso na sociedade. }\end{array}$ & 2012 & $\begin{array}{l}\text { Mestrado em Educação } \\
\text { e Contemporaneidade. }\end{array}$ \\
\hline 20 & $\begin{array}{l}\text { A Palavra e a Escola. Negociação e Conflito no } \\
\text { Trabalho com a Lei } 10.639 / 03 \text {. }\end{array}$ & 2012 & $\begin{array}{l}\text { Mestrado em Educação } \\
\text { e Contemporaneidade. }\end{array}$ \\
\hline 21 & $\begin{array}{l}\text { Trabalhadoras domésticas: trajetórias escolares e } \\
\text { (possíveis) caminhos profissionais. }\end{array}$ & 2012 & $\begin{array}{l}\text { Mestrado em Educação } \\
\text { e Contemporaneidade. }\end{array}$ \\
\hline
\end{tabular}

11 Data de publicação retificada do texto de Laffin e Dantas (2015, p. 155), segundo CDI http://www.cdi.uneb.br/site/wp-content/uploads/2016/01/adriana dos santos marmori lima.pdf.

12 Data de publicação retificada do texto de Laffin e Dantas (2015, p. 156), segundo CDI (http://www.cdi.uneb.br/site/wp-content/uploads/2018/06/CRIZEIDE-completo.docx).

Revista Educação e Ciências Sociais (ISSN: 2595-9980), Salvador, v.3, n.4, 2020 


\begin{tabular}{|c|c|c|c|}
\hline $\mathrm{N}^{\circ}$ & Título & Ano & Programa \\
\hline 22 & $\begin{array}{l}\text { Diálogos e silenciamentos interculturais em uma turma } \\
\text { de Educação de Jovens e Adultos no Terreiro. }\end{array}$ & 2012 & $\begin{array}{l}\text { Mestrado em Educação } \\
\text { e Contemporaneidade. }\end{array}$ \\
\hline 23 & $\begin{array}{l}\text { A leitura na Educação de Jovens e Adultos: } \\
\text { experiências e representações. }\end{array}$ & 2012 & $\begin{array}{l}\text { Mestrado em Estudo } \\
\text { de Linguagens. }\end{array}$ \\
\hline 24 & $\begin{array}{l}\text { As Práticas Socioculturais no Currículo da Educação } \\
\text { de Jovens e Adultos em Alagoinhas. }\end{array}$ & 2012 & $\begin{array}{l}\text { Mestrado Acadêmico } \\
\text { em Crítica } \\
\text { Cultural }\end{array}$ \\
\hline 25 & $\begin{array}{l}\text { Educação e relações raciais: um olhar sobre a } \\
\text { Educação de Jovens e Adultos no bairro da Rua Nova } \\
\text { na cidade de Feira de Santana. }\end{array}$ & 2013 & $\begin{array}{l}\text { Mestrado em Educação } \\
\text { e Contemporaneidade. }\end{array}$ \\
\hline 26 & $\begin{array}{l}\text { Educação de Jovens e Adultos na Rede Municipal de } \\
\text { Ensino de Salvador: processo de implantação da } \\
\text { economia solidária como componente curricular. }\end{array}$ & 2013 & $\begin{array}{l}\text { Mestrado em Educação } \\
\text { e Contemporaneidade. }\end{array}$ \\
\hline 27 & $\begin{array}{l}\text { A formação de professores (as) e a educação } \\
\text { multicultural no cenário da Educação de Jovens e } \\
\text { Adultos. }\end{array}$ & 2013 & $\begin{array}{l}\text { Mestrado em Educação } \\
\text { e Contemporaneidade. }\end{array}$ \\
\hline 28 & $\begin{array}{l}\text { Política de EJA da Rede Estadual: implantação e } \\
\text { implementação da proposta curricular tempo formativo } \\
\text { no Colégio Estadual Luís Cabral. }\end{array}$ & 2013 & $\begin{array}{l}\text { Mestrado Profissional } \\
\text { em Gestão e } \\
\text { Tecnologias Aplicadas } \\
\text { à Educação. }\end{array}$ \\
\hline 29 & $\begin{array}{l}\text { Tempo de plantar, tempo de colher: mulheres idosas, } \\
\text { saberes de si e aprendizagens de letramento em } \\
\text { Saquinho. }\end{array}$ & 2014 & $\begin{array}{l}\text { Doutorado em } \\
\text { Educação e } \\
\text { Contemporaneidade }\end{array}$ \\
\hline 30 & A obrigatoriedade escolar na Bahia (1870-1899). & 2014 & $\begin{array}{l}\text { Mestrado em Educação } \\
\text { e Contemporaneidade. }\end{array}$ \\
\hline 31 & $\begin{array}{l}\text { A Luta Social Ensina: O Direito à Educação na Vida } \\
\text { de Mulheres e Homens Sisaleiros - Assentamento } \\
\text { Nova Palmares - Conceição Do Coité - Bahia. }\end{array}$ & 2014 & $\begin{array}{l}\text { Doutorado em } \\
\text { Educação e } \\
\text { Contemporaneidade. }\end{array}$ \\
\hline 32 & $\begin{array}{l}\text { Experiências, narrativas e experimentações: o estágio } \\
\text { supervisionado do curso de Ciências Biológicas em } \\
\text { classes de Educação de Jovens e Adultos. }\end{array}$ & 2015 & $\begin{array}{l}\text { Mestrado em Educação } \\
\text { e Contemporaneidade }\end{array}$ \\
\hline 33 & $\begin{array}{l}\text { Filme "Vida Maria" como estímulo para narrativas } \\
\text { orais de experiências pessoais. }\end{array}$ & 2015 & $\begin{array}{l}\text { Mestrado Profissional } \\
\text { em Letras. }\end{array}$ \\
\hline 34 & $\begin{array}{l}\text { Poesia de cordel: leitura e letramentos na Educação de } \\
\text { Jovens e Adultos - EJA Alagoinhas Bahia. }\end{array}$ & 2016 & $\begin{array}{l}\text { Mestrado em Crítica } \\
\text { Cultural. }\end{array}$ \\
\hline 35 & $\begin{array}{l}\text { Educação de Jovens e Adultos na Escola Municipal } \\
\text { Professor Roberto Santos no município de Jussara - } \\
\text { Bahia: o subir a ladeira. }\end{array}$ & 2016 & $\begin{array}{l}\text { Mestrado Profissional } \\
\text { em Educação e } \\
\text { Diversidade. }\end{array}$ \\
\hline 36 & $\begin{array}{l}\text { Projeto Político Pedagógico de EJA da Rede Municipal } \\
\text { de Ensino de Salvador: educação e estranhamento. }\end{array}$ & 2016 & $\begin{array}{l}\text { Mestrado Profissional } \\
\text { em Gestão e } \\
\text { Tecnologias Aplicadas à } \\
\text { Educação } \\
\end{array}$ \\
\hline 37 & $\begin{array}{l}\text { EJA no IF BAIANO: desafios e possibilidades para a } \\
\text { gestão educacional. }\end{array}$ & 2016 & $\begin{array}{l}\text { Mestrado Profissional } \\
\text { em Gestão e } \\
\text { Tecnologias Aplicadas à } \\
\text { Educação }\end{array}$ \\
\hline 38 & $\begin{array}{l}\text { A Gestão do PROEJA no Instituto Federal da Bahia - } \\
\text { um encontro de duas modalidades de ensino: quando } \\
\text { um mais um é mais do que dois. }\end{array}$ & 2016 & $\begin{array}{l}\text { Mestrado Profissional } \\
\text { em Gestão e } \\
\text { Tecnologias Aplicadas à } \\
\text { Educação }\end{array}$ \\
\hline
\end{tabular}


Estado da arte das produções stricto sensu em educação de jovens e adultos na ...

\begin{tabular}{|c|c|c|c|}
\hline $\mathrm{N}^{\circ}$ & Título & Ano & Programa \\
\hline 39 & $\begin{array}{l}\text { Etnomatemática e o diálogo entre os saberes dos } \\
\text { alunos de EJA do Território de Identidade do Sisal - } \\
\text { Ba. }\end{array}$ & 2017 & $\begin{array}{l}\text { Doutorado em Educação } \\
\text { e Contemporaneidade }\end{array}$ \\
\hline 40 & $\begin{array}{l}\text { Projeto político pedagógico da Educação de Jovens e } \\
\text { Adultos: concepções e proposições. }\end{array}$ & 2017 & $\begin{array}{l}\text { Mestrado Profissional } \\
\text { em Educação e } \\
\text { Contemporaneidade. }\end{array}$ \\
\hline 41 & $\begin{array}{l}\text { A gíria nossa de cada dia: o uso de gírias por estudantes } \\
\text { da EJA em situações interacionais de sala de aula. }\end{array}$ & 2017 & $\begin{array}{l}\text { Mestrado Profissional } \\
\text { em Letras. }\end{array}$ \\
\hline 42 & $\begin{array}{l}\text { Relatório de pesquisa Projeto Político Pedagógico para } \\
\text { educação em prisões: outras estratégias para outro } \\
\text { sujeito de direito. }\end{array}$ & 2017 & $\begin{array}{l}\text { Mestrado Profissional } \\
\text { em Gestão e } \\
\text { Tecnologias Aplicadas } \\
\text { à Educação } \\
\end{array}$ \\
\hline
\end{tabular}

Fonte: Laffin e Dantas (2015) e CDI (2019)

O Mestrado Profissional em Educação de Jovens e Adultos (MPEJA ${ }^{\mathbf{1 3}}$ ) foi aprovado e recomendado pela CAPES em 2012 e teve sua primeira turma formada em 2015. Veja a seguir as produções catalogadas até o ano de 2017.

Quadro 06: Dissertações Catalogadas MPEJA até 2017.

\begin{tabular}{|c|c|c|}
\hline $\mathbf{N}^{0}$ & Título & Ano \\
\hline 1 & $\begin{array}{l}\text { A dor e a delícia de tornar-se... professor da EJA: narrativas de si na construção } \\
\text { formativa de educadores do juvenil do município de Catu-Ba. }\end{array}$ & 2015 \\
\hline 2 & $\begin{array}{l}\text { Os saberes experienciais da formação do professor da EJA: o exemplo da rede } \\
\text { municipal de ensino de Lauro de Freitas - Ba. }\end{array}$ & 2015 \\
\hline 3 & $\begin{array}{l}\text { Itinerâncias na formação continuada de professores do PROEJA FIC: um espaço } \\
\text { de proposições. }\end{array}$ & 2015 \\
\hline 4 & $\begin{array}{l}\text { As práticas pedagógicas de articulação com o mundo do trabalho na Educação de } \\
\text { Jovens e Adultos: experiências do proeja no centro estadual de educação } \\
\text { profissional - CEEP Newton Sucupira / Salvador - Ba. }\end{array}$ & 2015 \\
\hline 5 & $\begin{array}{l}\text { A práxis pedagógica do estágio supervisionado, em Educação de Jovens e Adultos, } \\
\text { do curso de Pedagogia/Campus I /UNEB: desafios e perspectivas. }\end{array}$ & 2015 \\
\hline 6 & $\begin{array}{l}\text { As práticas pedagógicas de articulação com o mundo do trabalho na Educação de } \\
\text { Jovens e Adultos: experiências do proeja no centro estadual de educação } \\
\text { profissional - CEEP Newton Sucupira / Salvador - Ba. }\end{array}$ & 2015 \\
\hline 7 & $\begin{array}{l}\text { Formação de Educadores de Jovens e Adultos: um olhar reflexivo para o } \\
\text { desenvolvimento e o aperfeiçoamento da prática docente no município de Matina- } \\
\text { Ba. }\end{array}$ & 2015 \\
\hline 8 & A formação dos professores da EJA na perspectiva dos textos visuais. & 2015 \\
\hline 9 & $\begin{array}{l}\text { Saberes e fazeres: olhares sobre o currículo da EJA da Escola João Pereira } \\
\text { Vasconcelos, município de Mata de São João/Ba. }\end{array}$ & 2015 \\
\hline 10 & $\begin{array}{l}\text { Do caderno de receitas da vovó ao site do Curos de Cozinha: a construção do } \\
\text { conhecimento e a inovação tecnológica na EJA. }\end{array}$ & 2015 \\
\hline
\end{tabular}

13 O MPEJA visa a produção de conhecimentos, a atualização permanente dos avanços da ciência e das tecnologias, a formação e o aperfeiçoamento de profissionais na área da educação de jovens e adultos, atendendo às demandas sociais e profissionais. (https://portal.uneb.br/mpeja).

Revista Educação e Ciências Sociais (ISSN: 2595-9980), Salvador, v.3, n.4, 2020 


\begin{tabular}{|c|c|c|}
\hline $\mathbf{N}^{\mathbf{0}}$ & Título & Ano \\
\hline 11 & $\begin{array}{l}\text { Importância da arte na construção do conhecimento na Educação de Jovens e } \\
\text { Adultos, na rede pública de ensino de Salvador, na visão do professor formador e } \\
\text { dos educandos. }\end{array}$ & 2015 \\
\hline 12 & $\begin{array}{l}\text { A formação continuada do professor da EJA: modelagem do software auxilix para } \\
\text { práticas inovadoras. }\end{array}$ & 2015 \\
\hline 13 & $\begin{array}{l}\text { Histórias de vida: percursos de formação de licenciandos em pedagogia no campo } \\
\text { da EJA. }\end{array}$ & 2015 \\
\hline 14 & $\begin{array}{l}\text { Aprender é preciso: fatores socioambientais que afetam a aprendizagem dos alunos } \\
\text { da EJA, badameiros, numa abordagem multidisciplinar. }\end{array}$ & 2015 \\
\hline 15 & A formação inicial do pedagogo e os saberes necessários para atuar na EJA & 2015 \\
\hline 16 & $\begin{array}{l}\text { Currículo integrado e trabalho - a formação continuada do professor do } \\
\text { (PROEJA): uma pesquisa compreensiva e propositiva }\end{array}$ & 2015 \\
\hline 17 & $\begin{array}{l}\text { Entre grades e trancas: o currículo da Educação de Jovens e Adultos no conjunto } \\
\text { penal de Eunápolis-Ba. }\end{array}$ & 2015 \\
\hline 18 & $\begin{array}{l}\text { A articulação de uma proposta de formação de professores (as) a partir do diálogo } \\
\text { com os sujeitos da Educação de Jovens e Adultos no município de Bom Jesus da } \\
\text { Lapa - Ba. }\end{array}$ & 2015 \\
\hline 19 & $\begin{array}{l}\text { Educação em direitos humanos e a relação com a Educação de Jovens e Adultos } \\
\text { na perspectiva da formação da cidadania. A experiência do CEDHIA }\end{array}$ & 2015 \\
\hline 20 & Uso pedagógico dos textos multissemióticos na Educação de Jovens e Adultos & 2015 \\
\hline 21 & $\begin{array}{l}\text { O componente curricular da EJA no projeto dos cursos de língua estrangeira da } \\
\text { UNEB: uma perspectiva para a emancipação }\end{array}$ & 2015 \\
\hline 22 & $\begin{array}{l}\text { A formação profissional dos educadores que atuam no programa todos pela } \\
\text { educação-topa, no município de Irecê e a relação com a práxis pedagógica. }\end{array}$ & 2015 \\
\hline 23 & $\begin{array}{l}\text { Pedagogia da alternância: a permanência e o desempenho escolar no curso técnico } \\
\text { em agropecuária, PROEJA, IFBaiano Campus Santa Inês }\end{array}$ & 2015 \\
\hline 24 & $\begin{array}{l}\text { Currículo e culturas juvenis: um estudo de caso sobre as representações sociais dos } \\
\text { estudantes da Educação de Jovens e Adultos no município de Conceição da Feira- } \\
\text { Ba. }\end{array}$ & 2016 \\
\hline 25 & $\begin{array}{l}\text { Tecendo saberes e fazeres no currículo da Educação de Jovens e Adultos: um } \\
\text { estudo sobre representações sociais de profissionais da educação de uma escola } \\
\text { polo da cidade de Feira de Santana - Bahia. }\end{array}$ & 2016 \\
\hline 26 & $\begin{array}{l}\text { Protótipo de um ambiente virtual como ferramenta de apoio no processo de ensino- } \\
\text { aprendizagem no curso técnico de informática do Instituto Federal Baiano - } \\
\text { Campus Bom Jesus Da Lapa. }\end{array}$ & 2016 \\
\hline 27 & $\begin{array}{l}\text { Tecendo saberes e fazeres no currículo da Educação de Jovens e Adultos: um } \\
\text { estudo sobre representações sociais de profissionais da educação de uma escola } \\
\text { polo da Cidade de Feira de Santana - Bahia. }\end{array}$ & 2016 \\
\hline 28 & $\begin{array}{l}\text { A EJA na educação não formal - ecoalfabetização como possibilidade de } \\
\text { desenvolvimento e fortalecimento comunitário em Morros de Higino - Jussara - } \\
\text { Ba. }\end{array}$ & 2016 \\
\hline 29 & $\begin{array}{l}\text { Educação em direitos humanos e Educação de Jovens e Adultos: representações } \\
\text { sociais de professores e alunos sobre a inserção da temática direitos humanos no } \\
\text { currículo da EJA. }\end{array}$ & 2016 \\
\hline 30 & $\begin{array}{l}\text { Entre algemas e liberdade: prática docente e uso do livro didático de geografia na } \\
\text { Educação de Jovens e Adultos -EJA em Serrolândia- Ba. }\end{array}$ & 2016 \\
\hline 31 & $\begin{array}{l}\text { Letramento digital: contribuições para potencializar a aprendizagem em leitura e } \\
\text { escrita na EJA. }\end{array}$ & 2016 \\
\hline 32 & $\begin{array}{l}\text { Currículo e identidade campesina na Educação de Jovens e Adultos em Amargosa- } \\
\text { Ba. }\end{array}$ & 2016 \\
\hline 33 & $\begin{array}{l}\text { A política curricular da EJA na rede municipal de ensino de Salvador: um estudo } \\
\text { compreensivo e propositivo da "proposta tempos de aprendizagem" na perspectiva } \\
\text { dos atores curriculantes docentes. }\end{array}$ & 2016 \\
\hline
\end{tabular}

Revista Educação e Ciências Sociais (ISSN: 2595-9980), Salvador, v.3, n.4, 2020 
Estado da arte das produções stricto sensu em educação de jovens e adultos na ...

\begin{tabular}{|c|c|c|}
\hline $\mathbf{N}^{\mathbf{0}}$ & Título & Ano \\
\hline 34 & $\begin{array}{l}\text { Círculos de diálogos e práticas de letramentos com as TIC: saberes, fazeres e } \\
\text { interfaces com a EJA. }\end{array}$ & 2016 \\
\hline 35 & $\begin{array}{l}\text { "Rutuais" das práticas docentes na EJA nas narrativas da professora Jussara: } \\
\text { elementos para pensar a formação continuada. }\end{array}$ & 2016 \\
\hline 36 & $\begin{array}{l}\text { As TIC no contexto formativo da EJA: um olhar reflexivo sobre a vida escolar em } \\
\text { redes sociais de estudantes do PROEJA Salvador. }\end{array}$ & 2016 \\
\hline 37 & $\begin{array}{l}\text { Robótica educacional e o processo de (re) construção da autonomia dos sujeitos } \\
\text { educativos: uma experiência na Educação de Jovens e Adultos. }\end{array}$ & 2016 \\
\hline 38 & $\begin{array}{l}\text { O PRONERA e as lutas sociais de políticas de EJA: um estudo do projeto pé na } \\
\text { estrada no assentamento agroextrativista São Francisco - Serra do Ramalho - } \\
\text { Bahia. }\end{array}$ & 2016 \\
\hline 39 & $\begin{array}{l}\text { Educação em direitos humanos e Educação de Jovens e Adultos: representações } \\
\text { sociais de professores e alunos sobre a inserção da temática direitos humanos no } \\
\text { currículo da EJA. }\end{array}$ & 2016 \\
\hline 40 & $\begin{array}{l}\text { A Educação de Jovens e Adultos no Projeto Político Pedagógico e nas práticas } \\
\text { educativas em escolas da rede municipal de Feira de Santana-Ba. }\end{array}$ & 2016 \\
\hline 41 & $\begin{array}{l}\text { Demandas e desafios da docência na Comunidade de Atendimento Socioeducativo } \\
\text { de Salvador - CASE/SSA: professore (a)s que atuam na escolarização de jovens } \\
\text { em privação de liberdade. }\end{array}$ & 2016 \\
\hline 42 & $\begin{array}{l}\text { Letramento digital: contribuições para potencializar a aprendizagem em leitura e } \\
\text { escrita na EJA. }\end{array}$ & 2016 \\
\hline 43 & $\begin{array}{l}\text { Tessitura do conhecimento no currículo da Educação de Jovens e Adultos do } \\
\text { campo. }\end{array}$ & 2016 \\
\hline 44 & $\begin{array}{l}\text { As contribuições da pedagogia de Paulo Freire para pensar a cultura da paz na EJA: } \\
\text { anunciando orientações curriculares. }\end{array}$ & 2016 \\
\hline 45 & $\begin{array}{l}\text { A lei } n^{\circ} 10.639 / 03 \text { e as questões étnico-raciais no currículo do centro territorial de } \\
\text { educação profissional do sertão produtivo - Caetité/Ba: um estudo no curso } \\
\text { técnico em secretariado - PROEJA. }\end{array}$ & 2016 \\
\hline 46 & $\begin{array}{l}\text { Mobilização de cultura matemática por meio da resolução de problemas } \\
\text { matemáticos na Educação de Jovens e Adultos. }\end{array}$ & 2016 \\
\hline 47 & $\begin{array}{l}\text { Ressignificação do conhecimento: percepções sobre as vivências socioculturais no } \\
\text { currículo da EJA. }\end{array}$ & 2016 \\
\hline 48 & $\begin{array}{l}\text { Currículo e identidade campesina na Educação de Jovens e Adultos em Amargosa- } \\
\text { Ba. }\end{array}$ & 2016 \\
\hline 49 & $\begin{array}{l}\text { Diálogos formativos com o (a)s professores (a)s da EJA e os pressupostos teóricos } \\
\text { metodológicos freireanos. }\end{array}$ & 2016 \\
\hline 50 & Design didático na web: autoria colaborativa do professor em contexto da EJA. & 2016 \\
\hline 51 & Formação docente e TIC: a colaboração nas práticas pedagógicas da EJA. & 2017 \\
\hline 52 & $\begin{array}{l}\text { Gênero, e sexualidade na organização curricular: intervenções colaborativas na } \\
\text { formação dos sujeitos Jovens e Adultos. }\end{array}$ & 2017 \\
\hline 53 & $\begin{array}{l}\text { Modelagem matemática para uma aprendizagem significativa na Educação de } \\
\text { Jovens e Adultos. }\end{array}$ & 2017 \\
\hline 54 & $\begin{array}{l}\text { Entre o prescrito e o praticado: um estudo de caso sobre o currículo da EJA na } \\
\text { Escola Professor George Fragoso Modesto, Complexo Penitenciário Lemos de } \\
\text { Brito, em Salvador-Bahia. }\end{array}$ & 2017 \\
\hline 55 & $\begin{array}{l}\text { Educação socioambiental em EJA: um estudo de intervenção pedagógica com } \\
\text { estudantes do Colégio Estadual Polivalente de Castro Alves/Ba. }\end{array}$ & 2017 \\
\hline 56 & $\begin{array}{l}\text { Formação continuada na Educação de Jovens e Adultos: desafios e perspectivas } \\
\text { em três escolas públicas da rede municipal de ensino de Lauro De Freitas. }\end{array}$ & 2017 \\
\hline 57 & $\begin{array}{l}\text { Formação continuada e em serviço de professores da Educação de Jovens e } \\
\text { Adultos: a experiência do Centro Estadual De Educação Magalhães Neto - } \\
\text { Salvador-Ba. }\end{array}$ & 2017 \\
\hline
\end{tabular}

Revista Educação e Ciências Sociais (ISSN: 2595-9980), Salvador, v.3, n.4, 2020 


\begin{tabular}{|c|l|c|}
\hline $\mathbf{N}^{\mathbf{0}}$ & Título & Ano \\
\hline $\mathbf{5 8}$ & $\begin{array}{l}\text { O uso de materiais manipuláveis nas aulas de matemática no âmbito da Educação } \\
\text { de Jovens e Adultos. }\end{array}$ & 2017 \\
\hline $\mathbf{5 9}$ & Avaliação mediadora no processo de ensino e aprendizagem de Jovens e Adultos. & 2017 \\
\hline $\mathbf{6 0}$ & $\begin{array}{l}\text { A formação docente e o fenômeno da juvenilização na Educação de Jovens e } \\
\text { Adultos: desafios formativos. }\end{array}$ & 2017 \\
\hline $\mathbf{6 1}$ & \begin{tabular}{l} 
Direito à educação do jovem na EJA: a intervenção didática em direitos humanos \\
\hline $\mathbf{6 2}$
\end{tabular} & $\begin{array}{l}\text { Avaliação do ensino médio a distância na Educação de Jovens e Adultos do SESI } \\
\text { Bahia. }\end{array}$ \\
\hline $\mathbf{6 3}$ & $\begin{array}{l}\text { Projeto político pedagógico da Educação de Jovens e Adultos: concepções e e } \\
\text { proposições. }\end{array}$ & 2017 \\
\hline
\end{tabular}

Fonte: CDI, 2019.

\section{UNIVERSIDADE FEDERAL DA BAHIA (UFBA)}

Na Universidade Federal da Bahia - UFBA foi consultado no repositório os programas que estão ligados diretamente aos cursos de Educação, são eles: Mestrado Profissional em Educação: Currículo, Linguagens e Inovações Pedagógicas (MPED), Programa de PósGraduação em Educação (PPGE), Programa de Pós-Graduação em Ensino, Filosofia e História das Ciências (PPGEFHC), e Programa de Pós-Graduação Multidisciplinar e MultiInstitucional em Difusão do Conhecimento (DMMDC).

O Repositório Institucional (RI) da Universidade Federal da Bahia apresenta orientações que facilitam a procura de produções relacionadas a qualquer tema de interesse do visitante. O tópico comunidades e coleções conduzem até a página que reúne uma lista de trabalhos acadêmicos, entre artigos, dissertações, teses e etc. presentes no site, podem acessar a comunidade desejada e pesquisar por meio da palavra-chave, assim como optar por uma busca mais avançada, preenchendo os campos: data, ordem crescente ou decrescente de busca, filtros para refinar o resultado e a opção de número de publicações por página.

Quadro 07: Resultado do levantamento por Programa. ${ }^{14}$

\begin{tabular}{|c|c|c|c|}
\hline Programa & Produção & $\begin{array}{c}\mathbf{N}^{\circ} \text { de } \\
\text { trabalhos }\end{array}$ & $\begin{array}{c}\mathbf{N}^{\circ} \text { de trabalhos } \\
\text { sobre a Educação } \\
\text { de Jovens e } \\
\text { Adultos }\end{array}$ \\
\hline $\begin{array}{c}\text { Programa de Pós-Graduação em } \\
\text { Ensino, Filosofia e História das } \\
\text { Ciências }\end{array}$ & $\begin{array}{c}\text { Dissertações de } \\
\text { Mestrado }\end{array}$ & 69 & 0 \\
\cline { 2 - 4 } $\begin{array}{c}\text { Meses de Doutorado } \\
\text { Educação: Currículo, Linguagens e } \\
\text { Inovações Pedagógicas }\end{array}$ & $\begin{array}{c}\text { Dissertações de } \\
\text { Mestrado Profissional } \\
\text { em Educação- Projeto } \\
\text { de Intervenção }\end{array}$ & 65 & 0 \\
\hline
\end{tabular}

${ }^{14}$ Faltam 989 produções em processo de análise.

Revista Educação e Ciências Sociais (ISSN: 2595-9980), Salvador, v.3, n.4, 2020 
Estado da arte das produções stricto sensu em educação de jovens e adultos na ...

\begin{tabular}{|c|c|c|c|}
\hline Programa & Produção & $\begin{array}{c}\mathbf{N}^{\circ} \text { de } \\
\text { trabalhos }\end{array}$ & $\begin{array}{c}\mathbf{N}^{\circ} \text { de trabalhos } \\
\text { sobre a Educação } \\
\text { de Jovens e } \\
\text { Adultos }\end{array}$ \\
\hline $\begin{array}{c}\text { Programa de Pós-Graduação em } \\
\text { Educação }\end{array}$ & Teses de Doutorado & 415 & 6 \\
\cline { 2 - 4 } & $\begin{array}{c}\text { Dissertações de } \\
\text { Mestrado }\end{array}$ & 548 & 21 \\
\hline $\begin{array}{c}\text { Programa de Pós-graduação em } \\
\text { Letras e Linguística }^{15}\end{array}$ & $\begin{array}{c}\text { Dissertações de } \\
\text { Mestrado }\end{array}$ & & 2 \\
\hline $\begin{array}{c}\text { Mestrado Interdisciplinar e } \\
\text { Profissional em Desenvolvimento e } \\
\text { Gestão Social }\end{array}$ & & & 2 \\
\hline $\begin{array}{c}\text { Mestrado Profissional em } \\
\text { Matemática em Rede Nacional }\end{array}$ & & & 1 \\
\hline Mestrado Profissional em Letras & & & \\
\hline
\end{tabular}

Fonte: RI, 2019.

A Faculdade de Educação da UFBA reúne 1675 arquivos em PDF, divididos organizadamente em comunidades e suas respectivas coleções; sendo assim, essas coleções são abastecidas por livros e periódicos, artigos, teses, dissertações, trabalhos apresentados em eventos e especializações, buscando resultados sobre temáticas atreladas a EJA, a revisão do site seguiu o critério de acessar suas subcomunidades, que são programas e grupos com linhas de pesquisas direcionadas aos assuntos educacionais. Sabendo que o foco deste artigo é o encontro de dissertações e teses, houve a seleção nos programas, dessa forma:

Quadro 06: Dissertações e Teses catalogadas no repositório da UFBA - 2007-2017.

\begin{tabular}{|c|l|c|c|}
\hline $\mathbf{N} \mathbf{N}^{\mathbf{0}}$ & Título & Ano & Programa \\
\hline $\mathbf{0 1}$ & $\begin{array}{l}\text { Configurações identitárias numa turma de EJA: uma } \\
\text { leitura para além das margens. }\end{array}$ & 2007 & $\begin{array}{c}\text { Mestrado em Letras e } \\
\text { Linguística. }\end{array}$ \\
\hline $\mathbf{0 2}$ & $\begin{array}{l}\text { A formação escolar das mulheres ferroviárias de } \\
\text { Alagoinhas-BA (1950-1970). }\end{array}$ & 2007 & $\begin{array}{c}\text { Mestrado Acadêmico } \\
\text { em Educação }\end{array}$ \\
\hline $\mathbf{0 3}$ & $\begin{array}{l}\text { Desencontros entre teorias e propostas de alfabetização } \\
\text { de adultos na perspectiva da pessoa analfabeta. }\end{array}$ & 2008 & $\begin{array}{c}\text { Mestrado Acadêmico } \\
\text { em Educação }\end{array}$ \\
\hline $\mathbf{0 4}$ & $\begin{array}{l}\text { Pedagogia das emoções: uma compreensão da dimensão } \\
\text { emocional na educação profissional de jovens e adultos. }\end{array}$ & 2008 & $\begin{array}{c}\text { Mestrado Acadêmico } \\
\text { em Educação }\end{array}$ \\
\hline $\mathbf{0 5}$ & $\begin{array}{l}\text { Entre a roça e a cidade: identidades, discursos e saberes } \\
\text { na escola. }\end{array}$ & 2008 & $\begin{array}{l}\text { Doutorado do Programa } \\
\text { de Pós-Graduação em } \\
\text { Educação }\end{array}$ \\
\hline $\mathbf{0 6}$ & $\begin{array}{l}\text { Juventude na Educação de Jovens e Adultos: novos } \\
\text { sujeitos num velho cenário. }\end{array}$ & 2009 & $\begin{array}{c}\text { Mestrado Acadêmico } \\
\text { em Educação }\end{array}$ \\
\hline
\end{tabular}

\footnotetext{
15 Dados em análise.

${ }^{16}$ Dados em análise.

17 idem

18 idem
} 


\begin{tabular}{|c|c|c|c|}
\hline $\mathbf{N}^{0}$ & Título & Ano & Programa \\
\hline 07 & $\begin{array}{l}\text { Educação profissional de pessoas jovens e adultas: novo } \\
\text { campo da profissionalidade docente. }\end{array}$ & 2009 & $\begin{array}{l}\text { Mestrado Acadêmico } \\
\text { em Educação }\end{array}$ \\
\hline 08 & $\begin{array}{l}\text { A educação do trabalhador na perspectiva do } \\
\text { desenvolvimento territorial: o caso de EJA/ SESI no } \\
\text { Polo petroquímico de Camaçari. }\end{array}$ & 2009 & $\begin{array}{l}\text { Profissionalizante em } \\
\text { Desenvolvimento e } \\
\text { Gestão Social. }\end{array}$ \\
\hline 09 & $\begin{array}{l}\text { Memórias de leituras literárias de jovens e adultos } \\
\text { Alagoinhenses. }\end{array}$ & 2009 & $\begin{array}{l}\text { Doutorado do Programa } \\
\text { de Pós-Graduação em } \\
\text { Educacão }\end{array}$ \\
\hline 10 & $\begin{array}{l}\text { O PROEJA, seus benefícios e as baixas taxas de } \\
\text { conclusão em um dos cursos do programa. }\end{array}$ & $2010^{19}$ & $\begin{array}{l}\text { Mestrado Acadêmico } \\
\text { em Educação }\end{array}$ \\
\hline 11 & $\begin{array}{l}\text { Diversidade linguística e norma padrão: um estudo } \\
\text { sobre a formação linguística do professor da EJA. }\end{array}$ & 2010 & $\begin{array}{l}\text { Mestrado Acadêmico } \\
\text { em Educação }\end{array}$ \\
\hline 12 & $\begin{array}{l}\text { As relações dos alunos da EJA com as tecnologias } \\
\text { digitais: implicações e possibilidades na vida de cada } \\
\text { um. }\end{array}$ & 2011 & $\begin{array}{l}\text { Mestrado Acadêmico } \\
\text { em Educação }\end{array}$ \\
\hline 13 & $\begin{array}{l}\text { Educar para a Liderança Servidora: avaliação do } \\
\text { Programa de Articulação da Educação Básica do SESI } \\
\text { Com Educação Profissional do SENAI BA. }\end{array}$ & 2011 & $\begin{array}{c}\text { Mestrado } \\
\text { Interdisciplinar e } \\
\text { Profissional em } \\
\text { Desenvolvimento e } \\
\text { Gestão Social } \\
\end{array}$ \\
\hline 14 & $\begin{array}{l}\text { As relações dos alunos da EJA com as tecnologias } \\
\text { digitais: implicações e possibilidades na vida de cada } \\
\text { um. }\end{array}$ & 2011 & $\begin{array}{l}\text { Mestrado Acadêmico } \\
\text { em Educação }\end{array}$ \\
\hline 15 & $\begin{array}{l}\text { Estratégias para permanência percepções dos jovens e } \\
\text { adultos sobre abandono no processo de escolarização na } \\
\text { rede municipal de Educação de Salvador. }\end{array}$ & 2011 & $\begin{array}{l}\text { Mestrado Acadêmico } \\
\text { em Educação }\end{array}$ \\
\hline 16 & $\begin{array}{l}\text { Da formação do sujeito ao sujeito da formação: saberes } \\
\text { e experiências de jovens e adultos do PROEJA. }\end{array}$ & 2011 & $\begin{array}{l}\text { Mestrado Acadêmico } \\
\text { em Educação }\end{array}$ \\
\hline 17 & $\begin{array}{l}\text { O Centro Supletivo de Qualificação Profissional da } \\
\text { Fundação Divina Pastora: uma instituição escolar em } \\
\text { sua singularidade (1970-1996). }\end{array}$ & 2011 & $\begin{array}{l}\text { Mestrado Acadêmico } \\
\text { em Educação }\end{array}$ \\
\hline 18 & $\begin{array}{l}\text { O conhecimento curricular na visão de estudantes do } \\
\text { terceiro tempo formativo do (Sic) EJA. }\end{array}$ & 2012 & $\begin{array}{l}\text { Mestrado Acadêmico } \\
\text { em Educação }\end{array}$ \\
\hline 19 & $\begin{array}{l}\text { Ensino de língua portuguesa na Educação de Jovens e } \\
\text { Adultos: uma compreensão sobre a prática. }\end{array}$ & 2012 & $\begin{array}{l}\text { Mestrado Acadêmico } \\
\text { em Educação }\end{array}$ \\
\hline 20 & $\begin{array}{l}\text { Formação docente para educar jovens e adultos na } \\
\text { diversidade. }\end{array}$ & 2012 & $\begin{array}{l}\text { Mestrado Acadêmico } \\
\text { em Educação }\end{array}$ \\
\hline 21 & Consciência fonológica e indivíduos jovens e adultos & 2012 & $\begin{array}{l}\text { Mestrado Acadêmico } \\
\text { em Língua e Cultura }\end{array}$ \\
\hline 22 & $\begin{array}{l}\text { Ausências e emergências na formação de jovens e } \\
\text { adultos em Salvador - BA: considerações em torno do } \\
\text { ensino da gramática. }\end{array}$ & 2012 & $\begin{array}{l}\text { Doutorado Acadêmico } \\
\text { em Educação }\end{array}$ \\
\hline
\end{tabular}

\footnotetext{
${ }^{19}$ Data de publicação retificada do texto de Laffin e Dantas (2015, p. 158), segundo RI UFBA, https://repositorio.ufba.br/ri/handle/ri/8857
} 
Estado da arte das produções stricto sensu em educação de jovens e adultos na ...

\begin{tabular}{|c|c|c|c|}
\hline $\mathbf{N}^{\mathbf{0}}$ & Título & Ano & Programa \\
\hline 23 & $\begin{array}{l}\text { Ensino da Geometria Espacial para Jovens e Adultos em } \\
\text { um Curso Técnico em Saneamento. }\end{array}$ & 2013 & $\begin{array}{l}\text { Mestrado Profissional } \\
\text { em Matemática em } \\
\text { Rede Nacional. }\end{array}$ \\
\hline 24 & $\begin{array}{l}\text { Uma análise do processo de avaliação do Projeto de } \\
\text { Economia Solidária e Educação de Jovens e Adultos. }\end{array}$ & 2013 & $\begin{array}{l}\text { Mestrado do de Pós- } \\
\text { Graduação em } \\
\text { Educação }\end{array}$ \\
\hline 25 & $\begin{array}{l}\text { Uma margem outra: itinerâncias de jovens das classes } \\
\text { populares na educação superior. }\end{array}$ & 2013 & $\begin{array}{l}\text { Doutorado Acadêmico } \\
\text { em Educação }\end{array}$ \\
\hline 26 & $\begin{array}{l}\text { Estratégias para permanência - percepções dos jovens e } \\
\text { adultos sobre abandono no processo de escolarização } \\
\text { na Rede Municipal de Educação de Salvador. }\end{array}$ & 2014 & $\begin{array}{l}\text { Mestrado Acadêmico } \\
\text { em Educação }\end{array}$ \\
\hline 27 & $\begin{array}{l}\text { A oralidade como exercício do dizer de estudantes } \\
\text { trabalhadores da EJA. }\end{array}$ & 2014 & $\begin{array}{l}\text { Mestrado Acadêmico } \\
\text { em Educação }\end{array}$ \\
\hline 28 & $\begin{array}{l}\text { Proposta curricular por eixos temáticos na Escola } \\
\text { Municipal Professor Joel Americano Lopes: ponto de } \\
\text { partida e inovação no processo educativo da Educação } \\
\text { de Jovens e Adultos. }\end{array}$ & 2015 & $\begin{array}{l}\text { Mestrado Profissional } \\
\text { em Educação: } \\
\text { Currículo, Linguagens e } \\
\text { Inovações Pedagógicas }\end{array}$ \\
\hline 29 & $\begin{array}{l}\text { Aprendizagem da leitura, escrita e oralidade: um olhar } \\
\text { sobre percepções e práticas na EJA. }\end{array}$ & 2016 & $\begin{array}{l}\text { Doutorado do Programa } \\
\text { de Pós-Graduação em } \\
\text { Educação }\end{array}$ \\
\hline 30 & $\begin{array}{l}\text { Caminhos trilhados em versos: teatro, cordel e } \\
\text { educação de jovens e adultos. }\end{array}$ & 2016 & $\begin{array}{l}\text { Doutorado do Programa } \\
\text { de Pós-Graduação em } \\
\text { Educação }\end{array}$ \\
\hline 31 & $\begin{array}{l}\text { A oralidade como exercício do dizer de estudantes } \\
\text { trabalhadores da EJA. }\end{array}$ & 2017 & $\begin{array}{l}\text { Mestrado do de Pós- } \\
\text { Graduação em } \\
\text { Educação }\end{array}$ \\
\hline 32 & $\begin{array}{l}\text { A produção de saberes em diálogo com práticas de } \\
\text { letramento na educação de jovens e adultos. }\end{array}$ & 2017 & $\begin{array}{l}\text { Mestrado do de Pós- } \\
\text { Graduação em } \\
\text { Educação }\end{array}$ \\
\hline 33 & $\begin{array}{l}\text { Nossa história conta: relatos autobiográficos em práticas } \\
\text { de ensino aprendizagem. }\end{array}$ & 2017 & $\begin{array}{l}\text { Mestrado Profissional } \\
\text { em Letras. }\end{array}$ \\
\hline
\end{tabular}

Fonte: Laffin e Dantas (2015) e Repositório da UFBA (2019)

Durante a pesquisa foi possível catalogar 33 trabalhos sobre a Educação de Jovens e Adultos na Universidade Federal da Bahia, contudo ainda há muitas publicações a serem catalogadas. Ao analisar as produções do Programa de Pós-Graduação Multidisciplinar e Multi-Institucional em Difusão do Conhecimento (DMMDC) não foi identificada teses de Doutorado sobre a Educação de Jovens e Adultos. 


\section{UNIVERSIDADE ESTADUAL DE FEIRA DE SANTANA - UEFS}

As dissertações defendidas no PPGE/UEFS estão disponíveis para acesso público por meio do sistema de bibliotecas da UEFS, o qual é integrante da Biblioteca Digital Brasileira de Teses e Dissertações (BDTD). O quadro 08 traz as dissertações defendidas no período de 2013 a 2018. Consta-se que o mestrado da UEFS é recente.

O Programa de Pós-Graduação em Educação (PPGE) - Mestrado Acadêmico, da Universidade Estadual de Feira de Santana (UEFS), área de concentração Educação, Sociedade e Culturas, foi aprovado pela Resolução CONSEPE/UEFS 129/2010 e recomendado pela Coordenação de Aperfeiçoamento de Pessoal de Ensino Superior (CAPES) em dezembro de 2010. Suas atividades tiveram início no primeiro semestre de 2011, abrindo um ciclo de interiorização da pós-graduação em educação no estado da Bahia (www.ppge.uefs.br/modules/conteudo/conteudo.php?conteudo=28).

Quadro 08: Dissertações do Mestrado em Educação da UEFS

\begin{tabular}{|c|c|c|}
\hline $\begin{array}{l}\text { Autor/ano/título/folha/ } \\
\text { tipo de estudo }\end{array}$ & Palavras-chave & Resumo do estudo \\
\hline $\begin{array}{l}\text { Mamona (2017). Educação de } \\
\text { Jovens e } \\
\text { sdultos: reflexões } \\
\text { sobre a } \text { modalidade } \\
\text { formação } \quad \text { inicial } \\
\text { professores de matemática da } \\
\text { UEFS. }\end{array}$ & $\begin{array}{l}\text { Educação de } \\
\text { Jovens } \\
\text { Adultos. } \\
\text { Formação Inicial } \\
\text { de Professores de } \\
\text { Matemática. } \\
\text { Licenciatura em } \\
\text { Matemática. }\end{array}$ & $\begin{array}{l}\text { Investiga no âmbito da formação inicial de } \\
\text { professores de matemática, do Curso de } \\
\text { Licenciatura em Matemática da } \\
\text { Universidade Estadual de Feira de Santana } \\
\text { - UEFS, os conhecimentos necessários } \\
\text { para atuação na Educação de Jovens e } \\
\text { Adultos - EJA. }\end{array}$ \\
\hline $\begin{array}{l}\text { Mascarenhas } r(2016), \\
\text { PROJOVEM } r \text { urbano: } \\
\text { concepções de formação de } \\
\text { jovens e implicações como } \\
\text { política colaborativa }(\mathbf{2 0 0 5}- \\
\text { 2013). }\end{array}$ & $\begin{array}{l}\text { ProJovem } \\
\text { Urbano. } \\
\text { Juventude. } \\
\text { Política } \\
\text { Colaborativa. } \\
\text { Pedagogia das } \\
\text { Competências. } \\
\end{array}$ & $\begin{array}{l}\text { Problematiza as concepções de formação } \\
\text { de jovens do ProJovem Urbano e suas } \\
\text { possíveis implicações como Política } \\
\text { Colaborativa no período de } 2005 \text { a } 2013 \text {. }\end{array}$ \\
\hline \begin{tabular}{lcrr} 
Santana & (2015). & Ciências & da \\
natureza & no & \multicolumn{2}{c}{ Projovem } \\
Urbano: & discursos & de & um \\
currículo & inventado & e \\
praticado. & & &
\end{tabular} & $\begin{array}{l}\text { Ciências da } \\
\text { Natureza. } \\
\text { Cidadania. } \\
\text { Projovem } \\
\text { Urbano. }\end{array}$ & $\begin{array}{l}\text { Apresenta os resultados da pesquisa sobre } \\
\text { o tema de Ciências da Natureza que é } \\
\text { abordado no material didático do } \\
\text { Projovem Urbano com discussão sobre } \\
\text { Currículo, Ensino de Ciências e Políticas } \\
\text { Públicas voltadas para a Juventude. }\end{array}$ \\
\hline 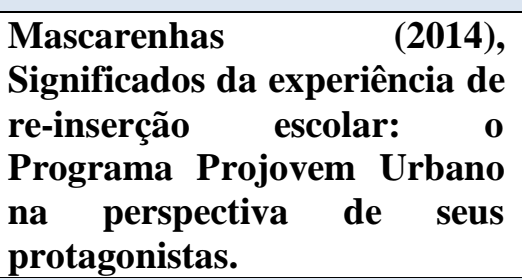 & $\begin{array}{l}\text { Juventude. Re- } \\
\text { inserção escolar. } \\
\text { Programa } \\
\text { Projovem } \\
\text { Urbano. Redes } \\
\text { de Significação. }\end{array}$ & $\begin{array}{l}\text { Investiga como adultos jovens que } \\
\text { vivenciaram uma trajetória escolar } \\
\text { irregular significam a experiência de } \\
\text { reinserção escolar no Programa Projovem } \\
\text { Urbano, na cidade de Feira de Santana, } \\
\text { Bahia. }\end{array}$ \\
\hline $\begin{array}{l}\text { Araújo (2014), Os sentidos da } \\
\text { escolarização para mulheres }\end{array}$ & $\begin{array}{l}\text { Gênero. } \\
\text { Rural/Campo. }\end{array}$ & $\begin{array}{l}\text { Apresenta um estudo de trajetórias de vida } \\
\text { e vivências escolares de mulheres adultas }\end{array}$ \\
\hline
\end{tabular}

Revista Educação e Ciências Sociais (ISSN: 2595-9980), Salvador, v.3, n.4, 2020 


\begin{tabular}{|c|c|c|}
\hline $\begin{array}{l}\text { Autor/ano/título/folha/ } \\
\text { tipo de estudo }\end{array}$ & Palavras-chave & Resumo do estudo \\
\hline $\begin{array}{l}\text { no rural de Feira de } \\
\text { Santana/Bahia: narrativas de } \\
\text { trajetórias e sonhos de } \\
\text { mulheres da EJA. }\end{array}$ & $\begin{array}{l}\text { História de vida. } \\
\text { Educação de } \\
\text { Jovens } \\
\text { Adultos. }\end{array}$ & $\begin{array}{l}\text { do rural do distrito de Maria Quitéria em } \\
\text { Feira de Santana-BA que retornaram à } \\
\text { escola na Educação de Jovens e Adultos } \\
\text { para a conclusão do ensino fundamental II. }\end{array}$ \\
\hline $\begin{array}{l}\text { Soares (2013), A relação } \\
\text { juventude e educação em } \\
\text { diferentes gerações: a } \\
\text { perspectiva de estudantes da } \\
\text { Educação de Jovens e Adultos } \\
\text { de uma escola municipal de } \\
\text { Feira de Santana - Ba. }\end{array}$ & $\begin{array}{l}\text { Juventude. } \\
\text { Educação. } \\
\text { Relações } \\
\text { intergeracionais. }\end{array}$ & $\begin{array}{l}\text { Analisa a relação juventude e educação na } \\
\text { perspectiva de estudantes de diferentes } \\
\text { gerações de uma escola municipal situada } \\
\text { em um bairro periférico da cidade de Feira } \\
\text { de Santana, Bahia. }\end{array}$ \\
\hline
\end{tabular}

Fonte: www.ppge.uefs.br/modules/conteudo/conteudo.php?conteudo=28, 2019.

\section{CONSIDERAÇÕES}

Este artigo apresenta os resultados parciais do projeto; até o momento foi possível identificar 144 produções Strictu Sensu sobre a Educação de Jovens e Adultos nos sites dos repositórios das universidades: UNEB (105 produções ${ }^{20}$ ), UFBA (19 produções), e UEFS (6 produções), e 37 produções no catálogo de Teses e Dissertações da CAPES.

Observou-se ao longo da pesquisa que os temas mais frequentes nas produções acadêmicas foram: alfabetização e letramento; planejamento e prática pedagógica; formação docente em EJA; evasão escolar; inclusão social; inclusão digital; exclusão social; desenvolvimento local sustentável; autoestima e afetividade; educação de jovens, adultos e idosos; gestão; representação social e; multiletramento. Também houve a identificação dos descritores-chave: direitos humanos, estudos étnicos raciais, currículo-educação e inclusão.

O estudo de Laffin e Dantas (2015) traz as categorias encontradas na pesquisa do estado do conhecimento da "A Pesquisa sobre a EJA na e da Bahia: aproximações e demandas teórico-metodológicas”, com levantamento de dados do período de 2003 a 2014, que analisa as investigações sobre e na Educação de Jovens e Adultos (EJA) no contexto da Bahia, bem como compreender/situar os principais objetos das pesquisas nas produções encontradas. Realizou-se o levantamento em diferentes repositórios brasileiros, via internet, e foram categorizados os estudos a respeito da temporalidade das pesquisas, dos objetos, dos referenciais teórico-metodológicos, dos autores mais recorrentes e das contribuições e resultados apresentados. Pode-se afirmar que ainda há grandes necessidades e possibilidades

\footnotetext{
${ }^{20}$ Dentre as 105 produções da UNEB são consideradas as 96 encontradas no CDI acrescidos dos 9 trabalhos catalogados a partir dos estudos de Laffin e Dantas, 2015.
}

Revista Educação e Ciências Sociais (ISSN: 2595-9980), Salvador, v.3, n.4, 2020 
de pesquisas em função de objetos pouco abordados, como: gênero, ERER, políticas públicas e formação docente, particularmente a inicial.

Quando iniciamos as atividades do projeto de pesquisa Gestão Social de Políticas Públicas de Educação de Jovens e Adultos na Bahia - 2007 a 2017 que trouxe como um dos subprojetos de iniciação científica "Análise sociológica da formação na Educação de Jovens e Adultos da Bahia", desconhecíamos a pesquisa das autoras Laffin e Dantas (2015), mas a mesma potencializou o confronto, a comparação e os avanços na busca de dados. Não cabe, aqui, repetir as autoras, mas recomendá-las como lastros iniciais da temática. E avançarmos, mesmo que parcialmente, no momento com os dados encontrados na conformação do objetivo de compreender as concepções sociológicas e educacionais que orientam as formulações governamentais e suas interfaces com as dinâmicas econômicas nos financiamentos e proposições de políticas públicas de formação para sujeitos da Educação de Jovens e Adultos - EJA.

O que se verifica nos estudos realizados é que grande maioria traz a concepção freireana de educação e de sociedade. É percebido, também, que algumas políticas públicas analisadas a exemplo dos programas governamentais (PROEJA, TOPA, Alfabetização Solidária) trazem na sua concepção teórico-metodológica os princípios freireanos da dialogicidade, conquista de autonomia, o respeito mútuo e a consciência da incompletude do ser, o homem libertando-se das opressões. E, nesta busca, percebe-se que um dos seguidores de Freire (2000) também tem sido referência nos últimos estudos principalmente dos que falam dos sujeitos da EJA. Trata-se de Arroyo (2005; 2008; 2011; 2014; 2017).

Como constatado por Laffin e Dantas (2015), os estudos na pós-graduação sobre a formação de professores na EJA ainda continuam com pouca representatividade de trabalhos sobre a formação inicial, o que impõe a necessidade de um mapeamento das pesquisas realizadas e o incremento das investigações nesta área, para poder potencializar a formação do professor e do sujeito educando que pretendemos que aprendam em comunhão, como dizia Freire.

Os estudos sobre professores e a formação docente na Educação de Jovens e Adultos - EJA refere-se:

$>$ Às necessidades formativas de alfabetizadores de adultos. Nestes aspectos, propomos enquanto políticas públicas o pensar em formação sólida e não em cursos aligeirados que respondem as demandas de programas; cria-se a expectativa de saberes docentes e perfil identitário do alfabetizador de EJA; 
A formação docente de professoras com enfoque nos conhecimentos sobre a educação multicultural e à aplicação nas práticas pedagógicas e à análise do programa de Formação Continuada, voltado aos professores da Educação de Jovens e Adultos (EJA) do Ensino Fundamental I e suas contribuições para o desenvolvimento profissional e possíveis mudanças da prática pedagógica das professoras.

Imagens e concepções docentes sobre o processo de letramento do surdo;

Perfil dos docentes de adultos;

A formação docente, narrativas e autobiografias;

$>$ As propostas pedagógicas e as práticas docentes.

Essas pesquisas transitam em interlocuções realizadas entre as práticas curriculares, considerando as identidades culturais dos estudantes e a pluralidade dos espaços interculturais nos quais se inclui a proximidade com a tradição cultural do candomblé; análise dos cursos, a partir dos sujeitos dos processos educativos; a construção de uma maquete tátil para estudantes de EJA cegos; conhecimento curricular na visão dos estudantes; políticas públicas no Programa Alfabetização Solidária e no programa Todos pela Alfabetização (Topa); a inserção das práticas socioculturais no Currículo da EJA; o ensino de matemática e biologia na EJA; políticas públicas e os fóruns de EJA; análise do programa Reaja; Processos de Educação do Campo e currículo na EJA; políticas de EJA e produção e do conhecimento nas universidades e a atuação da universidades em comunidades populares da Bahia.

Por último, contam-se com oito pesquisas que abordam o processo de educação profissional e EJA, com focos em: Educação profissional, novo campo de ensino e profissionalidade docente; ação comunitária e o PROJOVEM; liderança servidora na educação profissional do SENAI; o PROEJA e as baixas taxas de conclusão de cursos; Centro Supletivo (sic) e qualificação profissional; e, por último, o curso técnico em saneamento básico. (LAFFIN; DANTAS, 2015, p. 167).

Consideramos relevante continuação do estudo e seu aprofundamento na expectativa, quiçá, de formulação de projeto de política pública de formação permanente de professores da Educação de Jovens e Adultos que possa ser encaminhado à Secretaria de Educação do Estado e às Secretarias Municipais de Educação.

\section{REFERÊNCIAS}

ANGELUCCI, Carla Biancha et al. O estado da arte da pesquisa sobre o fracasso escolar (1991-2002): um estudo introdutório. In: Educação e Pesquisa, São Paulo, v. 30, n.1, p. 5172, jan. - abr. 2004. On-line version. ISSN 1678-4634. Disponível em: http://www.scielo.br/scielo.php?script=sci_arttext\&pid=S1517-97022004000100004. Acesso em: 20 jul. 2019. 
ARROYO, Miguel G. Os coletivos diversos repolitizam a formação. In: DINIZ-PEREIRA, Júlio E.; LEÃO, Gustavo (orgs.). Quando a diversidade interroga a formação docente. Belo Horizonte, MG: Autêntica, 2008, p. 11-36.

ARROYO, Miguel González. Currículo, território em disputa. Petrópolis, RJ: Vozes, 2011. ARROYO, Miguel González. Educação de jovens-adultos: um campo de direitos e de responsabilidade pública. In: SOARES, Leôncio; GIOVANETTI, Maria Amélia G. C.; GOMES, Nilma Lino (orgs.). Diálogos na educação de jovens e adultos. Belo Horizonte, MG: Autêntica, 2005. p. 19- 50.

ARROYO, Miguel González. Outros sujeitos, outras pedagogias. 2. ed. Petrópolis, RJ: Vozes, 2014.

ARROYO, Miguel González. Passageiros da noite: do trabalho para a EJA: itinerários pelo direito a uma vida justa. Petrópolis, RJ: Vozes, 2017.

BAHIA. Universidade do Estado da Bahia. Programa de Pós-Graduação em Educação e Contemporaneidade. Disponível em: 〈http://www.ppgeduc.uneb.br〉. Acesso?

BRASIL. Banco de teses da Coordenação de Aperfeiçoamento de Pessoal de Nível Superior. Disponível em: <http://www.capes.gov.br>. Acesso em: 04 mar. 2018.

FREIRE, Paulo. Pedagogia do oprimido. 28. ed. São Paulo: Paz e Terra, 2000.

BRASIL. Conselho Nacional de Educação. Resolução CNE nº 2, de 19 maio de 2010, que dispõe sobre as Diretrizes Nacionais para a oferta de educação de jovens e adultos em situação de privação de liberdade nos estabelecimentos penais. In: BRASIL. Ministério da Educação. Secretaria de Educação básica. Secretaria de Educação Continuada, Alfabetização, Diversidade e Inclusão. Secretaria de Educação Profissional e Tecnológica. Conselho Nacional de Educação. Câmara Nacional de Educação Básica. Diretrizes Curriculares Nacionais Gerais da Educação Básica. Brasília: MEC, SEB, DICEI, 2013.

BRASIL. Lei no 11.494, de 20 de junho de 2007 - Regulamenta o Fundo de Manutenção e Desenvolvimento da Educação Básica e de Valorização dos Profissionais da Educação FUNDEB. Disponível em: http://www.planalto.gov.br/ccivil_03/_ato2007- Acesso?

BRASIL. Lei no 13.005, de 25 de junho de 2014 (Plano Nacional de Educação (PNE) - 20142024). Disponível em <www.observatoriodopne.org.br/uploads/.../documentoreferencia.pdf>. Acesso em: 15 abr. 2015.

BRASIL. Lei no 9.394 de dezembro de 1996. Estabelece a Lei de Diretrizes e Bases da Educação Nacional. 5 ed. Brasília, DF: Câmara dos Deputados, 2010.

BRASIL. Ministério da Educação. Decreto no 2.208, de 17 de abril de 1997. Disponível em: <http://portal.mec.gov.br/seesp/arquivos/pdf/dec2208.pdf>. Acesso em: 15 abr. 2015.

BRASIL. Ministério da Educação. Decreto no 5.154, de 23 de julho de 2004. Disponível em < http://www.planalto.gov.br/ccivil_03/_Ato2004-2006/2004/Decreto/D5154.htm\#art9>. Acesso em: 15 abr. 2015. 
BRASIL. Portal de catálogo de teses e dissertações da CAPES. Disponível em: http://catalogodeteses.capes.gov.br/catalogo-teses/. Acesso em: data? jul./ago. 2018.

CDI UNEB - http://www.cdi.uneb.br/site/.

HADDAD, Sérgio; DI PIEERO, Maria Clara. Transformações nas políticas de Educação de Jovens e Adultos no Brasil no início do $3^{\circ}$ milênio: Uma análise das agendas nacional e internacional. Cad. Cedes, Campinas, volume 35, nº 96, páginas 197 - 217, 2015.

LAFFIN, Maria Hermínia Lage Fernandes; DANTAS, Tânia Regina. A pesquisa sobre a EJA na e da Bahia: aproximações e demandas teórico-metodológicas. Revista Brasileira de Educação de Jovens e Adultos, Bahia, v. 3, n. 6, 2015. Disponível em: https://www.revistas.uneb.br/index.php/educajovenseadultos/article/view/2139/1478. Acesso em: 08 maio. 2019.

NUNES, Eduardo José Fernandes; ARAÚJO, Sandra Regina Magalhães de; SANTOS, Lilian Almeida dos. Educação, gestão e desenvolvimento local: diálogos, práticas e emergências na EJA. Editora CRV, Curitiba, 2017.

NUNES, Eduardo José Fernandes; BARRETO, Maria Raidalva Nery; SANTOS, Marcos César Guimarães dos. A gestão social da EJA e suas interfaces com os movimentos sociais e a educação popular no Território de Identidade do Sisal - Bahia. Editora CRV, Curitiba, 2015.

REPOSITÓRIO da UEFS - www.ppge.uefs.br.

REPOSITÓRIO da UFBA - https://repositorio.ufba.br.

SZCEZEPANIK, Gilmar Evandro. A ciência e seus métodos: entre o monismo e o pluralismo metodológico. PERI, volume 9, n 1, páginas 221 - 238, 2017. 